\title{
Influence of Natural Fillers on Thermal and Mechanical Properties and Surface Morphology of Cellulose Acetate- Based Biocomposites
}

\author{
Nikola Španić $\mathbb{D},{ }^{1}$ Vladimir Jambreković $\mathbb{D},{ }^{1}$ Milan Šernek $\mathbb{D},{ }^{2}$ and Sergej Medved $\mathbb{D}^{2}$ \\ ${ }^{1}$ Department of Material Technologies, Faculty of Forestry, University of Zagreb, 10002 Zagreb, Croatia \\ ${ }^{2}$ Department of Wood Science and Technology, Biotechnical Faculty, University of Ljubljana, 1000 Ljubljana, Slovenia \\ Correspondence should be addressed to Nikola Španić; nspanic@sumfak.hr
}

Received 27 February 2019; Revised 29 April 2019; Accepted 22 May 2019; Published 27 June 2019

Academic Editor: Qinglin Wu

Copyright (C) 2019 Nikola Španić et al. This is an open access article distributed under the Creative Commons Attribution License, which permits unrestricted use, distribution, and reproduction in any medium, provided the original work is properly cited.

\begin{abstract}
In the present study, the influence of adding natural fillers to a cellulose acetate (CA) matrix, in order to develop biocomposites, on the properties of the achieved materials has been investigated. Extracted wood flour, holocellulose, and alpha cellulose were used as appropriate fillers. The results of the thermogravimetric analysis (TGA) and differential scanning calorimetry (DSC) of the fillers and biocomposites suggested the importance of the degree of degradation of filler properties, induced by the chemical treatment necessary for the preparation of the fillers, with emphasis on the content of lignin and the degradation of cellulose. Scanning electron microscopy (SEM) and mechanical analysis revealed that the matrix-filler ratio had a major effect on the prepared CAbased biocomposites, since polarity differences between the two major components caused the reduction of attractive forces in the matrix-filler relation, subsequently altering the properties of the developed materials.
\end{abstract}

\section{Introduction}

Biocomposites are sustainable, ecologically acceptable, and recyclable bio-based materials made from renewable resources [1]. The polymeric base of such materials is biopolymers [2], such as thermoplastic starch, polyhydoxyalkanoates (PHA), polylactides (PLA), lignin-based epoxy, soy-based resins, and epoxidised linseed oil [3]. Biocomposites can also be made using wood as raw material, which is, like all other materials of biological origin, characterized by a high degree of diversity and variability of properties, and which is additionally distinguished from the abovementioned materials due to its complex chemical composition. Considering its chemical composition, wood can be described as a three-dimensional biopolymer composite, comprising an interconnected network of cellulose, hemicellulose, and lignin, with a small share of inorganics and extractives $[4,5]$. The share of cellulose in wood, varying between $38 \%$ and $51 \%$, dependent on wood species and the method of its isolation $[4,6-9]$, alongside the possibility of chemical modification of cellulose by acetylation, emphasizes its use as a polymeric base in biocomposite materials. Therefore, the acetyl group bonding to the anhydroglucose units of cellulose directly affects the properties of cellulose acetate (CA) in terms of its biodegradability [10-12] and solubility in various solvents [13]. Exactly those properties are of key importance for the potential use of CA as the polymeric base for biocomposite materials. However, the degradation of cellulose and other chemical constituents of wood, alongside the difficulties related to the isolation of completely pure cellulose, limits the development of CA-based biocomposite materials. Regardless of that, CA is commercially used for the preparation of various membranes for reverse osmosis, gas separation, and micro-, nano-, and ultrafiltration [14-20]. Such applications of CA are almost exclusively based on the chemical modification of cellulose by acetylation and membrane preparation by the polymer spinning method or phase inversion and do not involve the interactions between cellulose matrices and fillers, as in the case of wood-based biocomposites. With the introduction of fillers into the structure of materials, the properties of the latter substantially change, since they no longer depend solely on 
the properties of the cellulose matrix but also on those of the fillers and their mutual interaction. In addition, the origin of the fillers is very important, as the situation is very different in the case of fillers of inorganic and organic origins. Fillers of inorganic origin, such as talc, kaolin, or zinc-borate, are easier to work with due to the isotropic properties of such materials. The properties of fillers of organic origin are highly dependent on the process of their isolation, which somewhat defines the limits of their usability because of their pronounced anisotropy [21]. Natural fillers in the form of cellulose nanofibrils and microfibrilated cellulose are suitable substitutions for inorganic fillers, whereby the size of the added particles is an essential factor affecting the strength, durability, and stability of lignocellulose-based biocomposite materials [22-24].

Lignocellulosic filler particle size and addition, alongside their chemical composition, have strong influence on various properties of composite materials (e.g., mechanical and thermal properties). Zaini et al. reported on the effect of filler content and size on the mechanical properties of polypropylene/oil palm wood flour composites with the conclusion that the composites filled with larger sized filler showed a higher modulus and tensile strength, especially at higher filler content [25]. Similar results for lignin-based date palm wood powder and rice husk-filled epoxy matrix were obtained by Rout and Satapathy [26] and AlMaadeed et al. [27], who reported high increase in mechanical and thermal properties (stability) of thus prepared composites, thus assigning cellulose as the chemical composition constituent responsible for mechanical property increase and lignin as responsible for the increase in thermal stability. Le Digabel and Avérous [28] obtained similar results for aromatic copolyester matrix filled with wheat straw particles and report that the addition of lignocellulosic fillers did not change the matrix crystallinity but influenced the nucleation process. David et al. [29] examined the influence of cellulosic filler particle addition on properties of biopolyester-based composites and revealed that intrinsic properties of polymeric matrix do not change significantly with the addition of cellulosic filler. Ni'mah et al. [30] examined the effect of the particle size and crystallinity of the cellulose filler on mechanical and thermal properties of poly(L-lactic acid) acid-based biocomposites. They report that the tensile strength decreases with the increase of the filler content, which is most probably due to filler particle agglomeration and that the composite strength and thermal stability rise with the rise in fillers' crystallinity. Treimanis et al. [31] examined the mechanical properties of hybrid composites with polyethylene and lignin matrix filled with microcrystalline cellulose and emphasized the importance that cellulose crystallinity and filler aspect ratios have on mechanical properties of such composites. Various authors report also on the influence that cellulose polymorphism (crystal structure) has on mechanical and thermal properties of polymer matrices filled with lignocellulosic fillers, where the cellulose II polymorph is described as one that significantly contributes the mentioned properties [32-36].

In order to determine the influence of filler type and chemical composition on the thermal and mechanical prop- erties, as well as the surface morphology of composites, in this study, CA-based biocomposite materials were prepared with different fillers, i.e., microsized particles of extracted wood, holocellulose, and alpha cellulose, and examined. Both the CA and the filler used in the formulation originated from the same wood species.

\section{Materials and Methods}

2.1. Materials. In this study, the white willow (Salix alba L.) and the black alder (Alnus glutinosa [L.] Gaertn.) wood were used as the basic raw material. Both wood species were sampled during mid-June and July 2013, in accordance with the TAPPI T $257 \mathrm{~cm}-12$ standard [37]. After sampling, the obtained wood samples were transported to the laboratory and allowed to dry naturally to $6-10 \%$ moisture content, before being debarked and milled using a Retsch SM 300 cutting mill. The obtained wood flour was screened, and particles sized between 0.5 and $1 \mathrm{~mm}$ were used for cellulose isolation and filler preparation.

Ethanol, benzene, nitric acid, acetic acid, sodium hydroxide, toluene, acetic anhydride, monopotassium salt of phthalic acid, and dichloromethane were all purchased from Kemika Ltd., Croatia. Sodium chlorite, perchloric acid, and pyridine were purchased from Sigma-Aldrich, Germany. All the chemicals and reagents were of analytical grade and were used without purification. Deionized water was used in all the experiments; it was prepared according to the ASTM type II specifications, using a TKA MicroMed system.

\subsection{Methods}

2.2.1. Cellulose Isolation and Filler Preparation. Prior to cellulose isolation, the wood flour of both wood species was extracted in a Soxhlet apparatus, according to the TAPPI T $204 \mathrm{~cm}-97$ standard [38], using a benzene/ethanol mixture $(1: 1 \% v / v)$ as the appropriate solvent. A part of the extracted wood flour was set aside in closed PE containers and later used as the filler, while the other part was used for further cellulose and holocellulose preparation. Kürschner-Hoffer's cellulose was used as the starting material for CA synthesis. It was prepared according to Browning [39], using an ethanol/nitric acid mixture $(4: 1 \% v / v)$. Holocellulose was prepared from extracted wood by Wise's method, slightly modified as described in Browning [39], using acetic acid and sodium chlorite. Alpha cellulose was prepared by the treatment of the previously isolated cellulose with sodium hydroxide $(17.5 \% w / v)$. The insoluble part of cellulose treated with sodium hydroxide, left on the filtering crucible after filtration, and drying at $103 \pm 2^{\circ} \mathrm{C}$ was considered to be pure alpha cellulose, as described in the TAPPI T $203 \mathrm{~cm}-99$ standard [40]. Prior to their use, all the fillers were additionally milled using an IKA analytical mill, screened to pass the $0.2 \mathrm{~mm}$ sieve, and dried at $60 \pm 2^{\circ} \mathrm{C}$ for $24 \mathrm{~h}$. Lengths and diameters of the thus-prepared filler particles were determined using a Zeiss Axio Zoom.V16 microscope equipped with a $5.0 \mathrm{Mpx}$ digital camera. The dimensions of 100 randomly chosen particles (per filler) 
TABLE 1: L/D ratios of fillers.

\begin{tabular}{lcc}
\hline Type of filler & \multicolumn{2}{c}{ L/D ratio } \\
& White willow & Black alder \\
\hline Extracted wood & 5.03 & 5.20 \\
Holocellulose & 6.30 & 6.41 \\
Alpha cellulose & 3.65 & 3.52 \\
\hline
\end{tabular}

were measured using Zeiss Axio vision software, and their length/diameter (L/D) ratios were calculated and expressed as mean values (Table 1 ).

\subsubsection{Cellulose Acetylation and CA Characterization. Cellu-} lose was acetylated as described in our earlier work [41]. Briefly, $100 \mathrm{~g}$ of cellulose (per wood species) was treated for 1 minute with a reaction mixture consisting of $500 \mathrm{ml}$ of acetic acid, $1000 \mathrm{ml}$ of toluene, and $5 \mathrm{ml}$ of perchloric acid as the catalyst. After $1 \mathrm{~min}, 500 \mathrm{ml}$ of acetic acid was added to the reaction mixture. Acetylation was conducted at ambient temperature, and the process took 45 minutes, after which $1000 \mathrm{ml}$ of deionized water was added to the reaction mixture in order to precipitate the CA. The obtained CA was then vacuum filtered and washed repeatedly with $1000 \mathrm{ml}$ of ethanol and $1000 \mathrm{ml}$ of deionized water until the strong acetic acid scent faded. The thus-prepared CA was dried for $8 \mathrm{~h}$ at $40^{\circ} \mathrm{C}$ and afterwards used for biocomposite preparation. After acetylation and drying, CA was analysed according to ASTM D 81796 [42] in order to determine the acetyl content (\% acetyl) and the degree of substitution (DS). Monopotassium salt of phthalic acid was used for the blanks and pyridine as the appropriate solvent. The CA obtained from white willow had $38.5 \%$ acetyl and 2.32 DS, while that from black alder had $42.5 \%$ acetyl and 2.73 DS.

2.2.3. Preparation of Biocomposites. Neat CA films and biocomposites were prepared by the solvent cast method using dichloromethane as the appropriate solvent. The CA was dissolved in a glass laboratory beaker, to which a known amount of solvent was added $(5 \% w / v)$. The prepared mixtures $(50 \mathrm{ml})$ were then poured into $110 \mathrm{~mm}$ inner diameter glass Petri dishes (with covers) that were put on a levelled surface in order to obtain films of uniform thickness. Biocomposites were prepared by adding various fillers $(10 \% w / w)$ to the already dissolved CA and by pouring the mixtures into Petri dishes. The CA prepared from a certain wood species was filled with fillers prepared from the same species. The cast neat $\mathrm{CA}$ and biocomposite mixtures were left undisturbed in covered Petri dishes for three days at room temperature, during which the solvent evaporated and thin films were formed. For each wood species and each type of filler, three replications were made. An IKA electromagnetic stirrer was used for dissolving the CA and for the dispersion of filler particles. The repeatability of the film thickness (as measured using an INSIZE digital micrometer (model 3100-25; $0.001 \mathrm{~mm}$ precision) and expressed as the standard deviation of 50 measurements) was $0.0113 \mathrm{~mm}$.

\subsection{Characterization}

2.3.1. Thermogravimetric Analysis. The thermal behaviour of the fillers was evaluated by thermogravimetric analysis (TGA), which was carried out on a PerkinElmer Pyris 1 TGA analyser, at temperatures ranging from $50^{\circ} \mathrm{C}$ to $700^{\circ} \mathrm{C}$, with a heating rate of $10^{\circ} \mathrm{C} / \mathrm{min}$, under a synthetic airflow of $30 \mathrm{ml} / \mathrm{min}$. The derivation of the TG curves, in order to obtain DTG curves, was done using Pyris Ver. 11 software.

2.3.2. Differential Scanning Calorimetry. The thermal properties of the neat CA films and biocomposites were determined by differential scanning calorimetry (DSC), which was carried out on a PerkinElmer DSC 6000 by heating and cooling the samples $(\sim 5 \mathrm{mg})$ from $30^{\circ} \mathrm{C}$ to $315^{\circ} \mathrm{C}$, using a scanning rate of $10^{\circ} \mathrm{C} / \mathrm{min}$, under a nitrogen flow of $20 \mathrm{ml} / \mathrm{min}$. The melting $\left(T_{\mathrm{m}}\right)$ and crystallization $\left(T_{\mathrm{c}}\right)$ temperatures were taken as the peak temperatures of the melting endotherm and the crystallization exotherm. Glass transition $\left(T_{\mathrm{g}}\right)$ temperature was calculated as the point on the curve where the specific heat change is half of the change in the completed transition (half $C_{\mathrm{p}}$ extrapolated). The value of $58.8 \mathrm{~J} / \mathrm{g}$ [43] as the heat of fusion of a perfect crystal of CA was used to determine the degree of crystallinity.

2.3.3. FT-IR Analysis. Fourier transform infrared (FT-IR) spectra were recorded on a Shimadzu FTIR-8400S spectrometer by the $\mathrm{KBr}$ pellet method, in the range of $4000-400 \mathrm{~cm}^{-1}$, with the resolution of $4 \mathrm{~cm}^{-1}$. Subsequent processing of the obtained results was performed using IRSolution Ver.1.30 software.

2.3.4. XRD Analysis. Diffraction patterns of fillers were taken by a Philips diffractometer PW1820 having a proportional counter and a graphite monochromator with $\mathrm{CuK} \alpha$ radiation in Bragg-Brentano geometry. Patterns were recorded in the $2 \Theta$ range $5-70^{\circ}$, with the step size of $0.02^{\circ} /$ step with the recording time of $1 \mathrm{~s} / \mathrm{step}$.

The crystallinity index $\left(I_{\mathrm{C}}\right)$ was calculated from the ratio of the areas of the crystalline region (under peaks $\left(11^{-} 0\right.$ ), (110), and (020)) and the total area in the XRD pattern as reported by Jin et al. [44].

2.3.5. Mechanical Properties. Tensile tests were performed in accordance with the ASTM D882-02 [45] standard on a Zwick/Roell Z005 universal testing machine. Thin strips $(\sim 60 \times 10 \times 0.25 \mathrm{~mm})$ of neat CA films and biocomposites were prepared using a surgical blade and were examined at the cross-head speed of $1 \mathrm{~mm} / \mathrm{min}$. The dimensions of the thin strips were determined using an INSIZE digital calliper (model 1137-150; $0.01 \mathrm{~mm}$ precision) and an INSIZE digital micrometer (model 3100-25; $0.001 \mathrm{~mm}$ precision). The values reported in this study represent the mean values of 10 measurements. Statistical analysis of the obtained results was performed using Statistica Ver.13.3 software (TIBCO Software Inc.).

2.3.6. Surface Morphology. The images of surface morphology were collected on a TESCAN MIRA/LMU scanning electron microscope (SEM). In order to increase the conductivity 
TABLE 2: Summary of TGA data on wood and different types of fillers used.

\begin{tabular}{|c|c|c|c|c|c|}
\hline Material & $T_{\mathrm{o}}\left({ }^{\circ} \mathrm{C}\right)$ & $T_{10 \%}\left({ }^{\circ} \mathrm{C}\right)$ & $T_{50 \%}\left({ }^{\circ} \mathrm{C}\right)$ & $T_{85 \%}\left({ }^{\circ} \mathrm{C}\right)$ & $\mathrm{DTG}_{\max }\left({ }^{\circ} \mathrm{C}\right)$ \\
\hline \multicolumn{6}{|l|}{ White willow } \\
\hline Nonextracted wood & 314.9 & 276.2 & 335.5 & 436.0 & 335.9 \\
\hline Extracted wood & 316.9 & 273.8 & 335.5 & 436.0 & 337.9 \\
\hline Holocellulose & 304.9 & 263.3 & 331.2 & 408.8 & 330.0 \\
\hline Alpha cellulose & 318.8 & 301.3 & 346.7 & 473.8 & 341.8 \\
\hline \multicolumn{6}{|l|}{ Black alder } \\
\hline Nonextracted wood & 315.4 & 267.0 & 335.0 & 436.7 & 336.8 \\
\hline Extracted wood & 314.1 & 272.9 & 334.6 & 434.6 & 336.4 \\
\hline Holocellulose & 310.4 & 273.3 & 331.8 & 394.7 & 334.2 \\
\hline Alpha cellulose & 317.7 & 289.5 & 340.4 & 472.6 & 337.9 \\
\hline
\end{tabular}

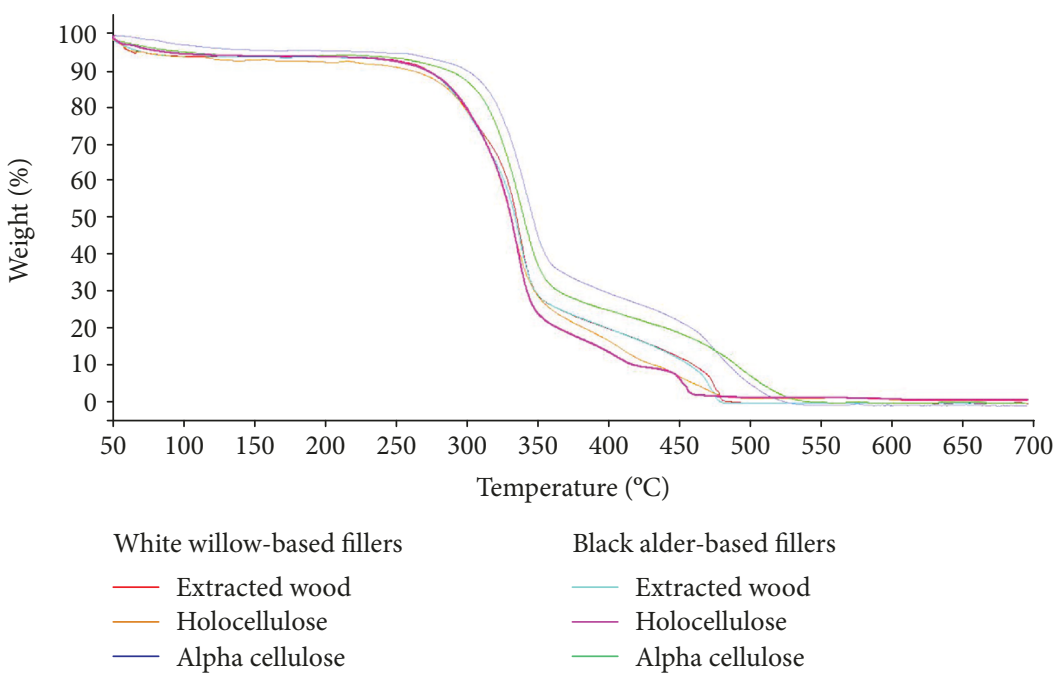

Figure 1: TG curves of wood fillers.

of the mounted specimens, they were coated with gold/palladium on a Quorum Technologies sputter coater, model SC7620-CF Mini.

2.3.7. UV-VIS Spectroscopy and Porosity Test. UV-VIS spectroscopy was performed in order to determine the percentage transmittance $(\% \mathrm{~T})$ of the neat CA films. Thin strips were cut using a surgical blade and mounted on the film holder, and their \% $\mathrm{T}$ was determined according to the ASTM D 1003-07 standard [46], on a Shimadzu UVmini-1240 spectrophotometer.

The porosity test was performed according to Wang et al. [47] by immersion of thin strips of neat CA films into deionized water $\left(20^{\circ} \mathrm{C}\right)$ for $1 \mathrm{~h}$ and subsequent film drying in a vacuum oven at reduced pressure for $4 \mathrm{~h}$.

\section{Results and Discussion}

3.1. Thermal Characterization of Fillers and Biocomposites. Biocomposites were prepared using white willow (Salix alba L.) and black alder (Alnus glutinosa [L.] Gaertn.) wood flour as the starting material for both CA synthesis and filler preparation. Their thermal properties were determined using differential scanning calorimetry (DSC). Supplementary data were obtained from the thermogravimetric analysis (TGA), Fourier transform infrared (FT-IR) spectroscopy, and X-ray diffraction (XRD) of the fillers.

3.1.1. Thermal Properties of Fillers. TGA was conducted on the fillers in a stream of synthetic air in order to obtain data relevant to the functional environment that they would be used in. The TGA results of the fillers are given in Table 2 and in Figure 1, while representative TG-DTG curves of extracted wood flour are presented in Figure 2.

As expected, due to oxidative atmosphere, sample degradation occurred in two stages, as indicated by the formation of two distinctive peaks on the DTG curves of all of the examined fillers. The first step (peak) represents primary sample degradation, and the second one could be related to oxidative degradation of the residues or completion of lignin degradation as its thermal stability is very high, and thus, it degrades over a wide temperature range $[48,49]$. The formation of peak shoulders (marked in Figure 2) in the case of unextracted wood flour, extracted wood flour, and holocellulose from both wood species indicates two-step degradation of cellulose and hemicelluloses with partial overlapping with 


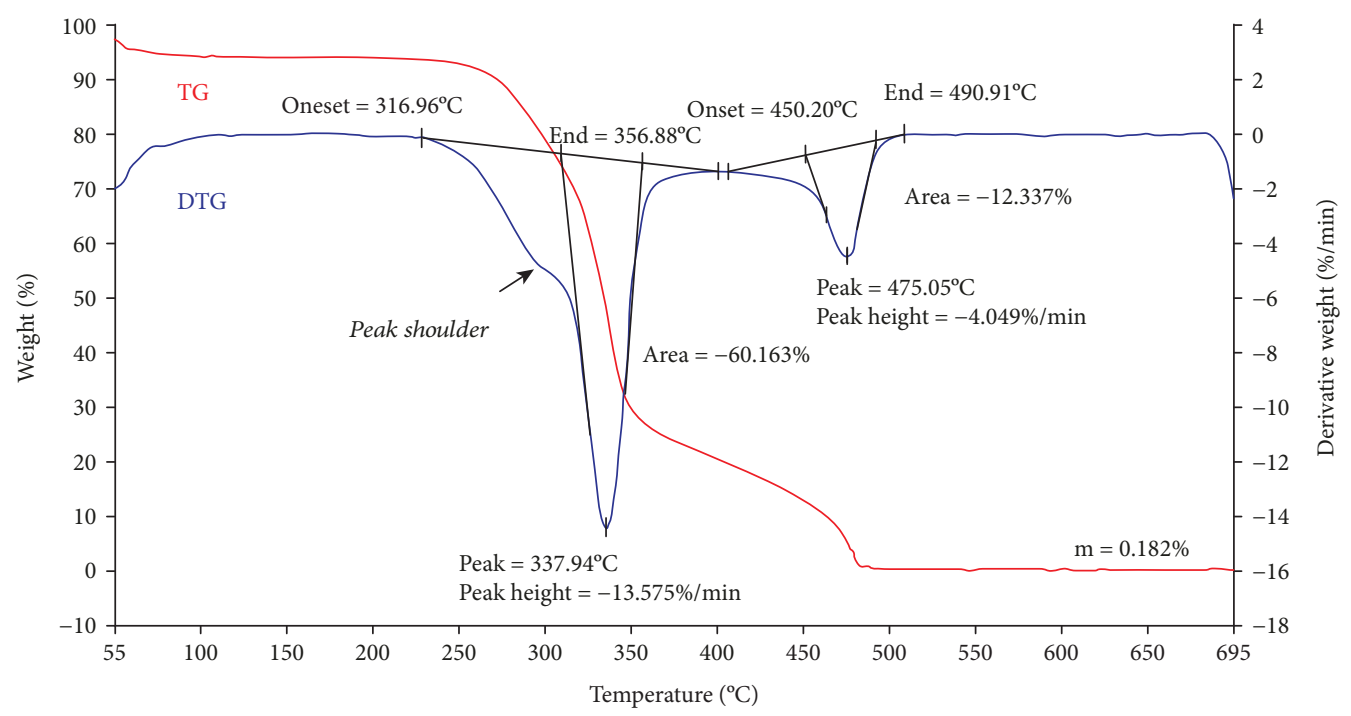

FIGURE 2: TG-DTG curves of extracted wood flour (white willow).

lignin [50]. The peak shoulders of unextracted wood flour and extracted wood flour, in the case of white willow, appear at $296.4^{\circ} \mathrm{C}$ and $295.7^{\circ} \mathrm{C}$, respectively. In the case of black alder, the peak shoulders appear at $295.3^{\circ} \mathrm{C}$ and $298.3^{\circ} \mathrm{C}$, respectively. Such narrow distribution and small differences of the peak values indicate the presence of other components, different in each species, which affect the thermal stability of cellulose and hemicelluloses [50]. As in the case of both wood species, extraction was performed using a benzene/ethanol mixture and part of the organic extractives had been removed, leading to small differences in thermal stability between unextracted wood flour and extracted wood flour (Table 2), which is in correspondence with the results reported in previous studies [51, 52]. The peak shoulder of holocellulose prepared from white willow appears at $297.4^{\circ} \mathrm{C}$ and of that from black alder at $296.0^{\circ} \mathrm{C}$. As holocellulose is composed of cellulose and hemicelluloses, the formation of shoulders at lower temperature could be attributed to the degradation of hemicelluloses, while higher temperature peaks can be attributed to cellulose degradation [50, 53-56].

Although the TGA results are comparable and are within measurement error, data presented in Figure 1, alongside the $T_{\mathrm{o}}$ and $T_{85 \%}$ values for holocellulose fillers given in Table 2 , suggest the decrease of their thermal stability. As XRD analysis showed that the crystallinity index of holocellulose prepared from both wood species is higher than that of extracted wood (Table 3), the thermal stability decrease could be associated with partial degradation and seclusion of lignin caused by prolonged chemical treatment in the process of holocellulose preparation. Lignin decomposes much slower and over a broader temperature range than cellulose and hemicelluloses [48,49,57,58], so its seclusion directly impacted the thermal stability of the holocellulose prepared from both wood species.

In order to obtain additional information on the chemical composition of the prepared holocellulose, FT-IR analysis
TABLE 3: Crystallinity indices of fillers.

\begin{tabular}{lcc}
\hline Type of filler & \multicolumn{2}{c}{ Crystallinity index (\%) } \\
& White willow & Black alder \\
\hline Extracted wood & 56 & 41 \\
Holocellulose & 58 & 50 \\
Alpha cellulose & 62 & 67 \\
\hline
\end{tabular}

Note: deconvoluted diffraction peaks for holocellulose prepared from black alder and alpha cellulose prepared from white willow are shown in the Supplementary information.

has been performed. As can be seen from Figure 3, in the fingerprint region of the FT-IR spectra of holocellulose, peaks related exclusively to carbohydrates are present.

The presence of a well-marked peak at $1738 \mathrm{~cm}^{-1}$ related to unconjugated $\mathrm{C}=\mathrm{O}$ in xylans (hemicelluloses), whose shape and intensity are almost the same in the case of both extracted wood flour and holocellulose from both wood species, suggests that the chemical treatments have not induced the degradation of hemicelluloses. The peak at $1640 \mathrm{~cm}^{-1}$, related to absorbed water, is more pronounced in the FT-IR spectra of holocellulose, which is explained by its preparation method. The absence of the low intensity peak formed at $1596 \mathrm{~cm}^{-1}$ and the intensity drop of the peak at $1508 \mathrm{~cm}^{-1}$ related to the $\mathrm{C}=\mathrm{C}$ stretching of the aromatic ring (lignin) in the FT-IR spectra of holocellulose indicate complete delignification. This is additionally confirmed by the absence of the peak at $1462 \mathrm{~cm}^{-1}$ and the intensity drop of the peak at $1426 \mathrm{~cm}^{-1}$ related to C-H deformations in lignin $[59,60]$. The formation and small intensity changes of the peaks at $1375 \mathrm{~cm}^{-1}$ (C-H deformations in cellulose and hemicellulose), $1324 \mathrm{~cm}^{-1}$ (C-H vibration in cellulose), $1253 \mathrm{~cm}^{-1}$ (C$\mathrm{O}$ stretch in hemicellulose), $1158 \mathrm{~cm}^{-1}$ (C-O-C vibrations in cellulose and hemicellulose), $1112 \mathrm{~cm}^{-1}$ and $1053 \mathrm{~cm}^{-1}$ (C-O stretch in cellulose and hemicellulose), and $895 \mathrm{~cm}^{-1}$ (C-H deformation in cellulose) $[59,61,62]$ clearly indicate that high-purity, lignin-free holocellulose was prepared. 


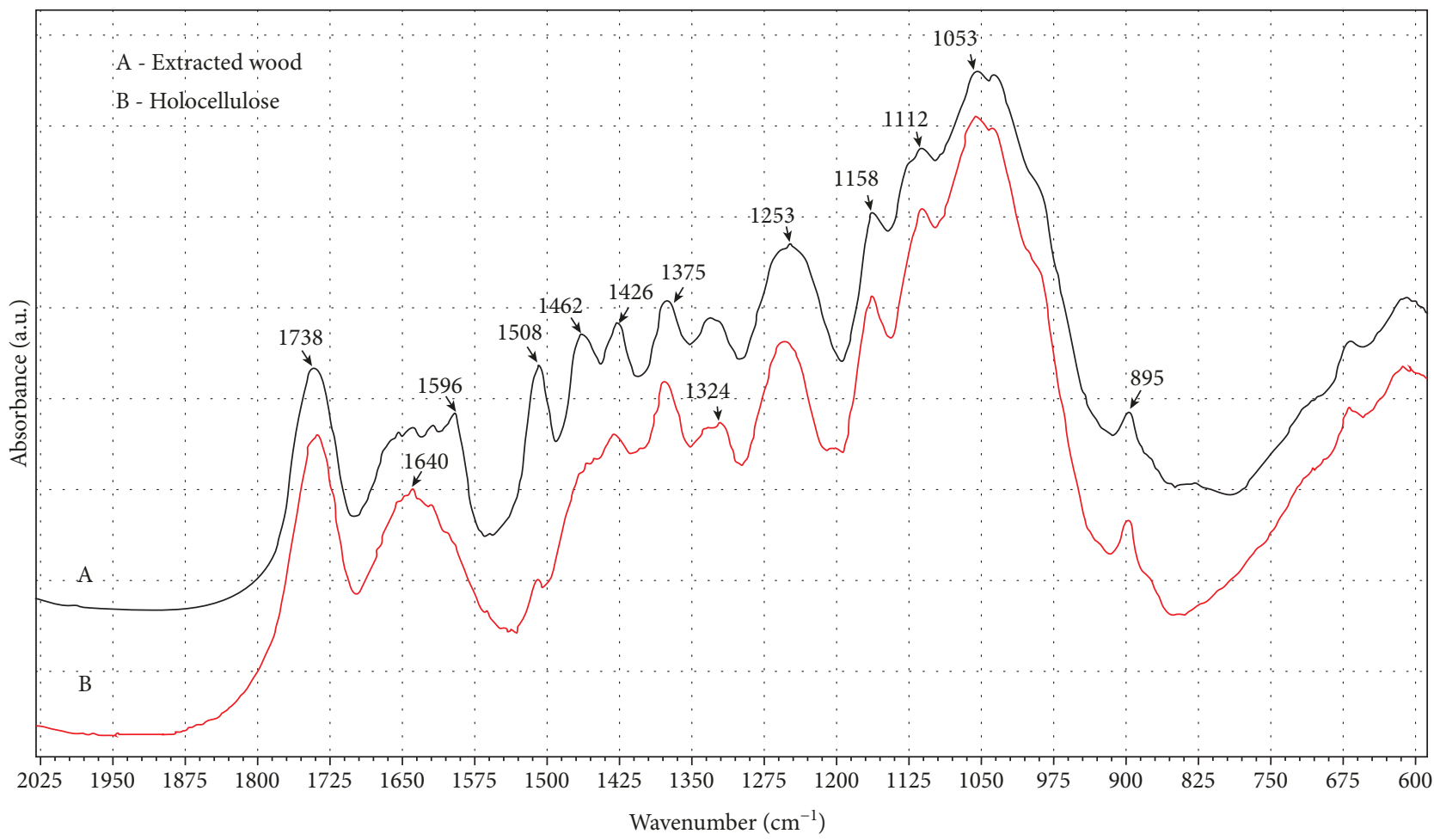

FIGURE 3: FT-IR spectra of extracted wood flour and holocellulose prepared from black alder.

Kürschner-Hoffer's cellulose treatment with sodium hydroxide solution caused cellulose II polymorphic form creation that was confirmed by XRD analysis (Figure 4). Samples S1, S2, S4, and S5 show a typical diffraction pattern for cellulose I, with the diffraction peaks at $2 \Theta$ around $14.5^{\circ}$, $16.5^{\circ}$, and $22.5^{\circ}$ corresponding to $\left(11^{-} 0\right)$, (110), and (200) maxima, respectively. This fully corresponds to the characteristic diffraction maxima of cellulose I [63]. XRD patterns of the samples S3 and S6 belong to cellulose II, with the Bragg intensities located at $2 \Theta$ around $12.0^{\circ}, 20.0^{\circ}$ and $22.0^{\circ}$ corresponding to $\left(11^{-} 0\right),(110)$, and (020) maxima, respectively [63]. Clear difference between the diffraction patterns of cellulose I and II samples can be seen from figures of deconvoluted diffraction peaks of samples S5 and S3 given in the Supplementary Material (available here).

As cellulose II is a more thermodynamically stable polymorphic form than cellulose I [64], it is easy to conclude why the $T_{\mathrm{o}}$ and $T_{85 \%}$ values for alpha celluloses are the highest among the examined fillers. Although almost identical regarding the TGA values (Table 2 ), there still is a small difference between the two alpha celluloses which was determined by additional postprocessing of the FT-IR results. The second derivative of alpha cellulose IR spectra (Savitzky-Golay method; 20 data points) in the $3800 \mathrm{~cm}^{-1}$ to $2700 \mathrm{~cm}^{-1}$ region of the FT-IR spectra (not shown in Figure 3 ) of both species revealed the formation of peaks characteristic of the two crystalline allomorphs, cellulose $\mathrm{I}_{\alpha}$, and cellulose $\mathrm{I}_{\beta}$, with cellulose $\mathrm{I}_{\beta}$ more pronounced in the case of white willow. As the monoclinic structure of allomorph $\mathrm{I}_{\beta}$ is thermodynamically more stable than the triclinic structure of allomorph $\mathrm{I}_{\alpha}$ [65], such distribution suggests that white willow should have slightly higher thermal stability, which corresponds with the TGA data (Table 2). The differences between the results obtained in our study and the values of characteristic $\mathrm{I}_{\alpha}$ and $\mathrm{I}_{\beta}$ peaks stated in the literature can be explained by the fact that the treatment of cellulose with $\mathrm{NaOH}$ solution resulted in the preparation of materials representing a mixture of two polymorphic varieties of cellulose, i.e., celluloses I and II [35], as confirmed in Figure 4.

3.1.2. Thermal Properties of Biocomposite Materials. The results of DSC analysis (Table 4, Figures 5 and 6) indicate that prolonged chemical treatment during the preparation of the fillers caused the decline of $T_{\mathrm{g}}, T_{\mathrm{m}}$, and $T_{\mathrm{c}}$ values of the biocomposites prepared from both wood species. However, this is only partially correct, as, with the inclusion of filler particles into the polymer matrix, the system is changed on a molecular level and it becomes directly influenced by the chemical composition of individual fillers.

As can be seen from Table 4 , the $T_{\mathrm{g}}$ values of neat CA matrices are slightly different which could be associated with possible differences of the CA's degree of polymerization and molecular weight. The $T_{\mathrm{g}}$ values correspond with the start of the translational motion of polymer chain segments that is generally independent of polymer molecular weight. However, in the molecular weight range where the degree of polymerization is low, the effects of chain ends lower the $T_{\mathrm{g}}$ values [66]. Such "plasticizing effect" of the end groups could be additionally affected with the presence of water in CA (moisture content of the CA prepared from white willow 


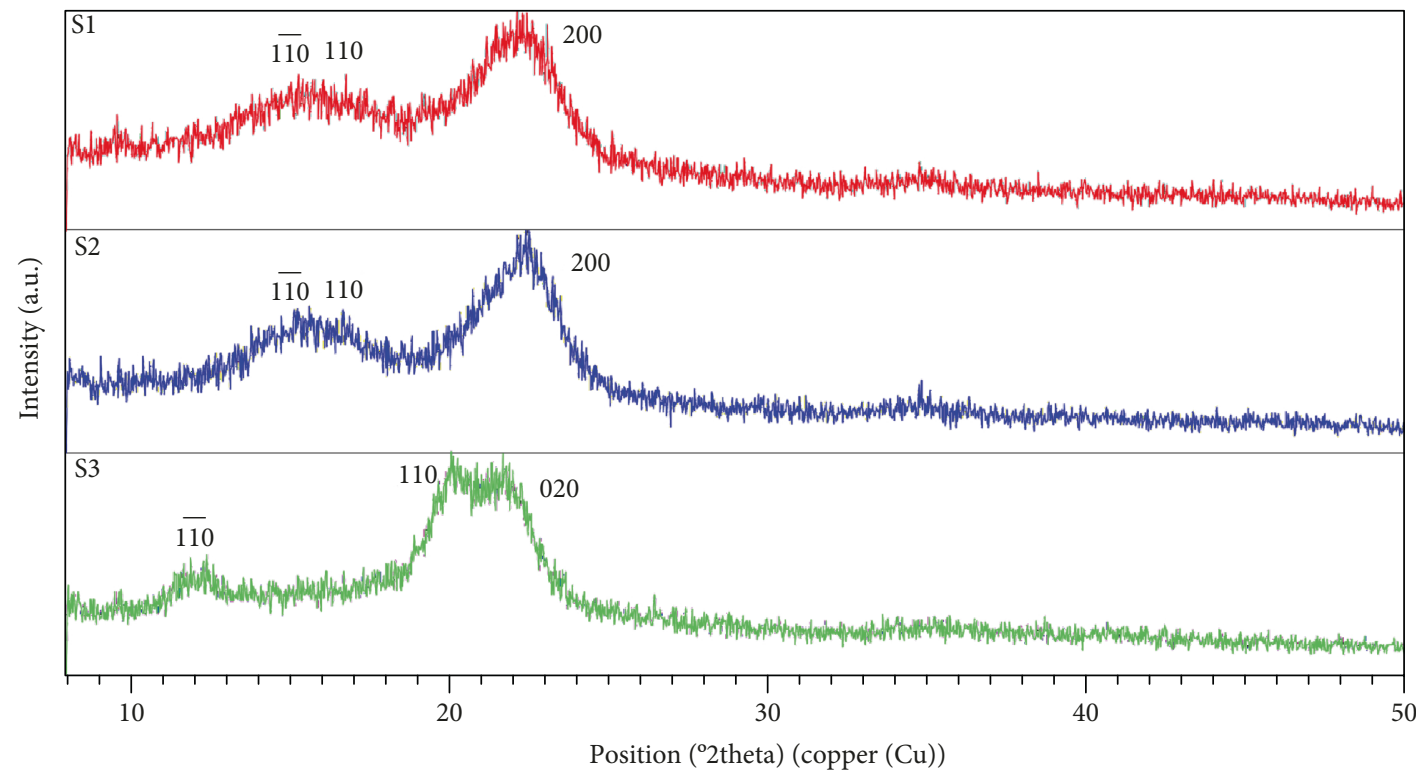

(a)

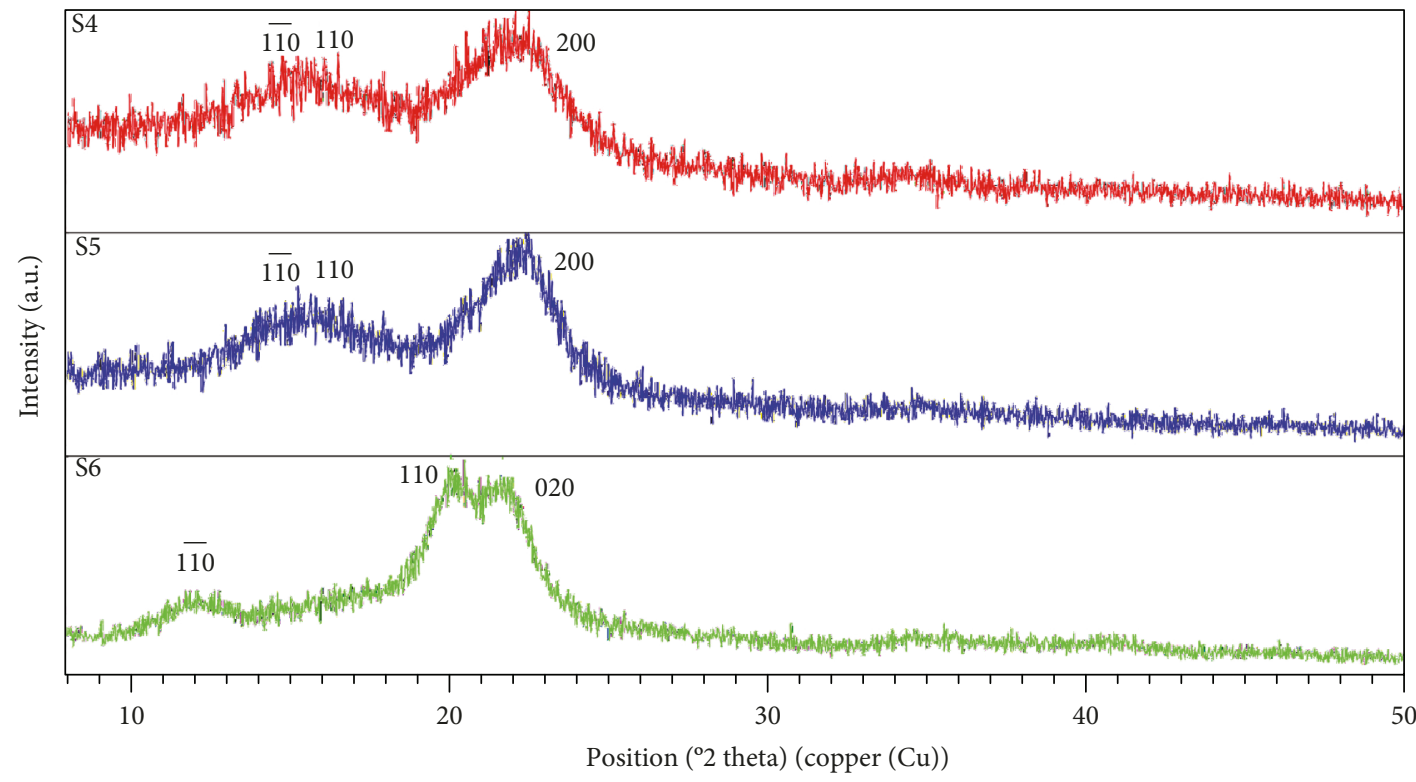

(b)

FIGURE 4: Characteristic XRD patterns of fillers ((a) white willow-based fillers, (b) black alder-based fillers; S1 (S4): extracted wood; S2 (S5): holocellulose; S3 (S6): alpha cellulose).

was $7.46 \%$, while for black alder it was $8.01 \%$ ). Due to its low molar mass, water acts as a plasticizer increasing the polymer free volume, thus shifting the $T_{\mathrm{g}}$ values to lower temperatures, which is more pronounced in the case of black alder and is in accordance with literature data regarding the influence of the plasticizer on $T_{\mathrm{g}}$ values $[67,68]$. As crude Kürschner-Hoffer cellulose was used as raw material for CA synthesis, during acetylation, acetic anhydride reacted with both cellulose and hemicellulose [69]. Therefore, the small difference in $T_{\mathrm{g}}$ values of neat matrices can also be attributed to the presence of xylan acetate acting as an internal plasticizer [70], which is more pronounced in black alder, as reported in our earlier work [41].
If the distributions of $T_{\mathrm{g}}, T_{\mathrm{m}}$, and $T_{\mathrm{c}}$ values (Table 4) are observed and compared with the TGA values of the individual fillers (Table 2), it can be assumed that the $T_{\mathrm{g}}$ values of composites are dependent on filler dispersion in the polymer matrix. As filler particles are larger $(\approx 200 \mu \mathrm{m})$ than the radius of gyration of the polymer matrix, the particle-rich phase segregates from the blend, resulting in a change of $T_{\mathrm{g}}$ values. This change is more prominent in the fillers from which larger quantities of lignin had been secluded, as it is responsible for filler agglomeration and the inhibition of cellulose molecule diffusion to the chains of the polymer matrix [35]. It must be emphasized that the statement above does not automatically imply that the polymer matrix-filler 
TABLE 4: DSC analysis of biocomposite materials.

\begin{tabular}{|c|c|c|c|c|c|c|}
\hline Type of filler & $T_{\mathrm{g}}\left({ }^{\circ} \mathrm{C}\right)$ & $T_{\mathrm{m}}\left({ }^{\circ} \mathrm{C}\right)$ & $T_{\mathrm{c}}\left({ }^{\circ} \mathrm{C}\right)$ & $\Delta \mathrm{H}_{\mathrm{m}}(\mathrm{J} / \mathrm{g})$ & $\Delta \mathrm{H}_{\mathrm{c}}(\mathrm{J} / \mathrm{g})$ & $X_{c}(\%)$ \\
\hline \multicolumn{7}{|l|}{ White willow } \\
\hline Neat CA & 177.8 & 303.6 & 254.4 & 25.5 & 18.7 & 11.6 \\
\hline Extracted wood & 178.0 & 304.6 & 257.8 & 26.9 & 16.0 & 20.5 \\
\hline Holocellulose & 177.5 & 304.5 & 252.1 & 18.7 & 13.0 & 10.8 \\
\hline Alpha cellulose & 176.6 & 303.9 & 247.6 & 19.7 & 16.0 & 7.0 \\
\hline \multicolumn{7}{|l|}{ Black alder } \\
\hline Neat CA & 173.1 & 305.7 & 263.2 & 25.0 & 18.5 & 11.1 \\
\hline Extracted wood & 178.3 & 307.3 & 267.7 & 21.3 & 14.6 & 12.8 \\
\hline Holocellulose & 177.3 & 306.7 & 265.2 & 20.5 & 15.1 & 10.3 \\
\hline Alpha cellulose & 176.6 & 306.3 & 262.6 & 18.2 & 13.5 & 8.9 \\
\hline
\end{tabular}

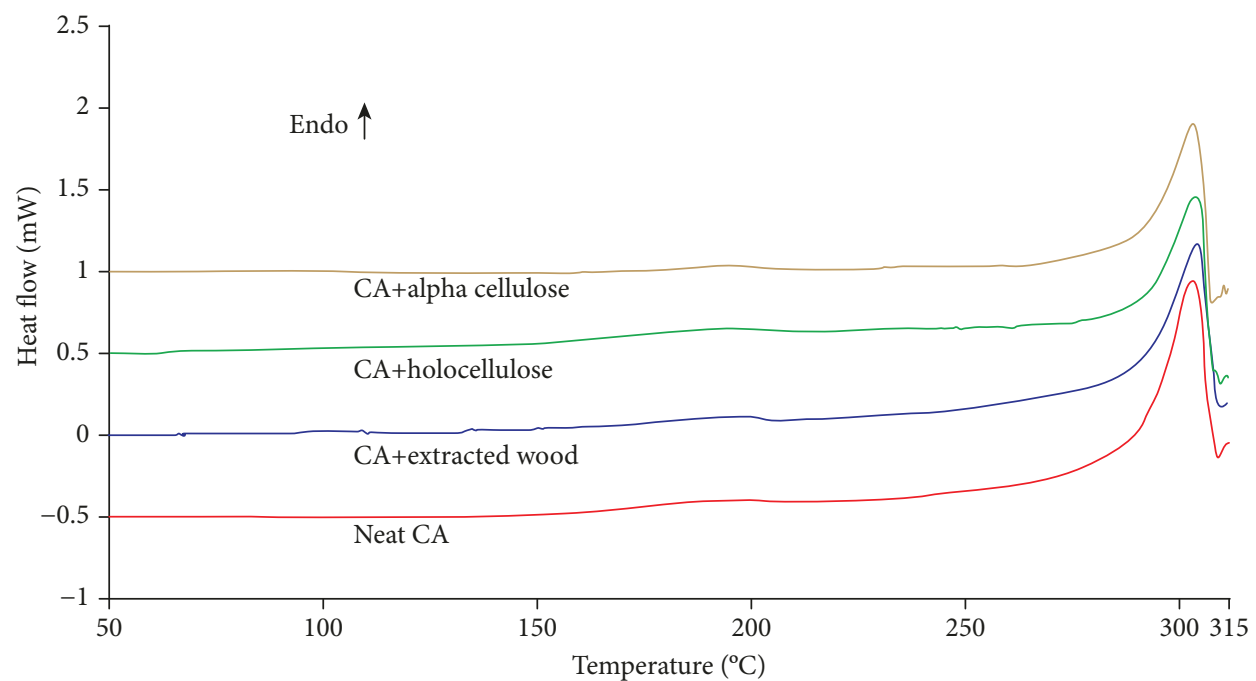

(a)

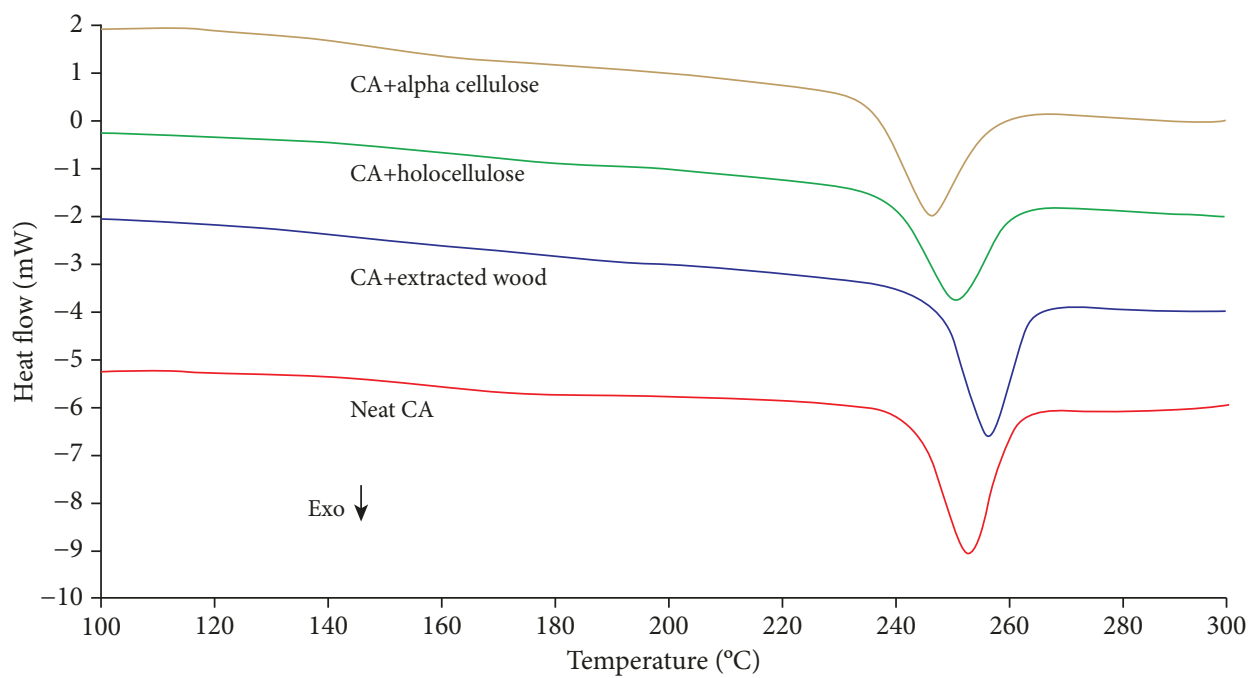

(b)

FIGURE 5: DSC curves of neat CA and biocomposites prepared from white willow: (a) heating endotherms; (b) cooling exotherms.

interaction is not satisfactory, but it confirms the influence of the filler on the rheology of the biocomposite materials. As $T_{\mathrm{m}}$ values are associated with the crystalline regions of bio- composite materials, they are highly dependent on filler purity, in terms of hemicellulose and lignin contents. Lignin is an amorphous, complex polymeric cross-linked aromatic 


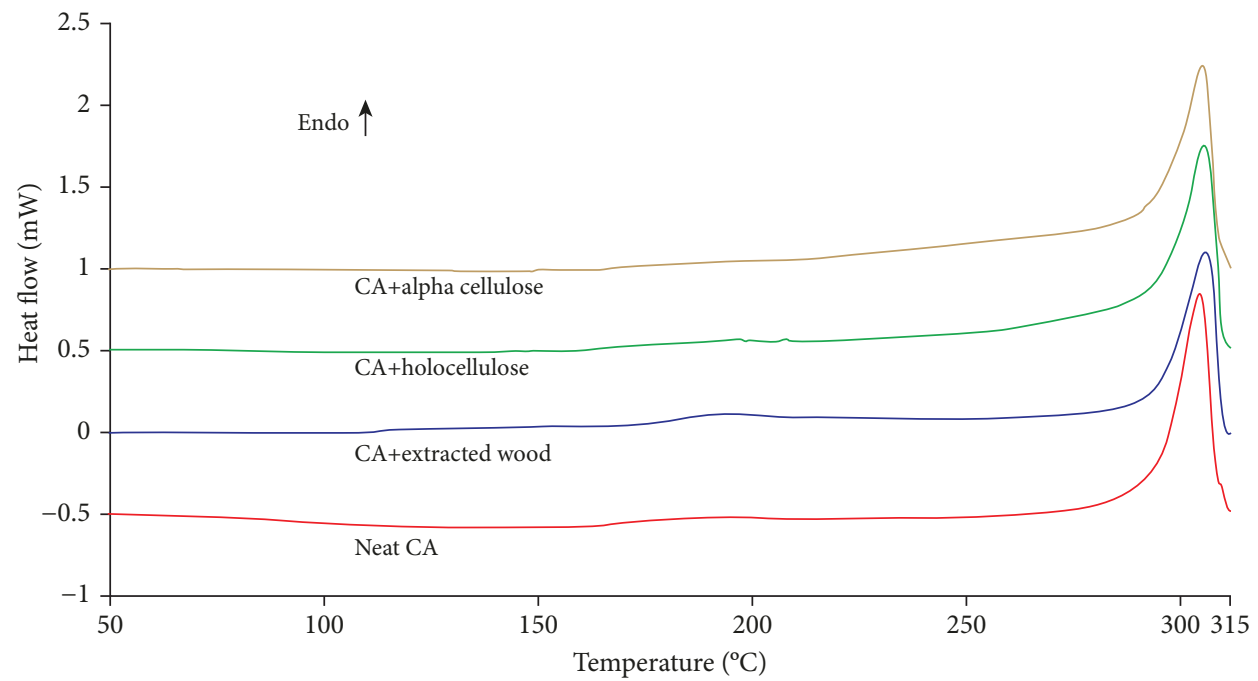

(a)

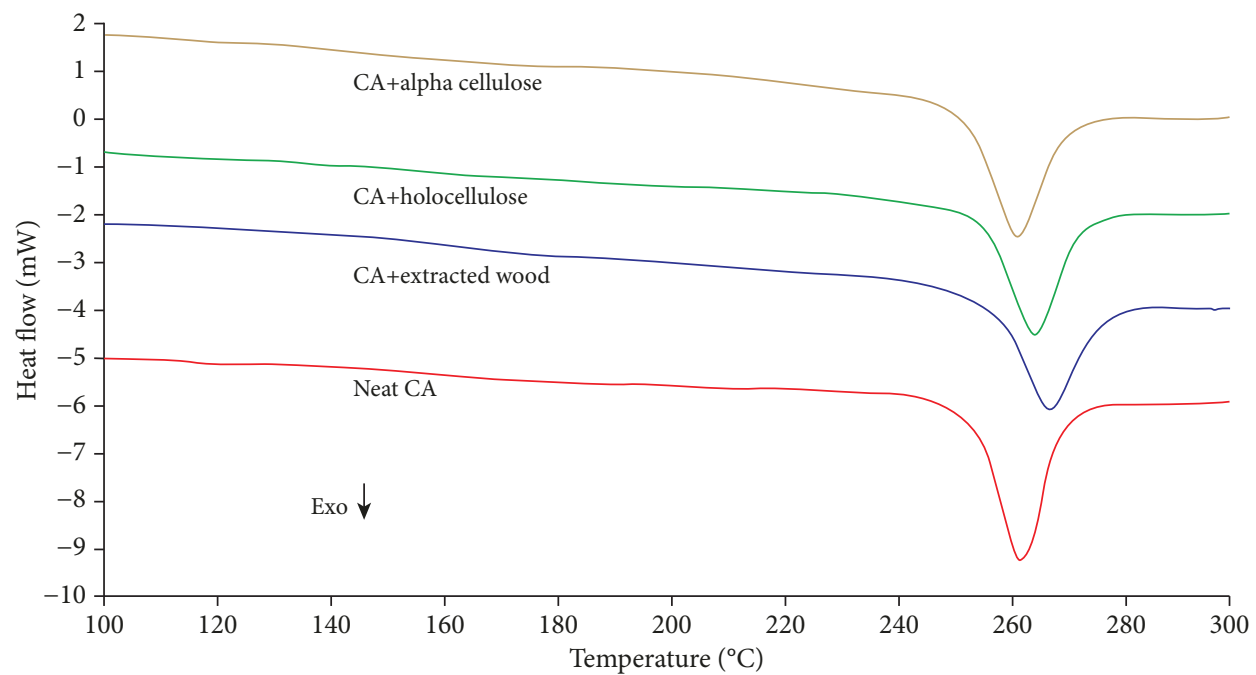

(b)

FIGURE 6: DSC curves of neat CA and biocomposites prepared from black alder: (a) heating endotherms; (b) cooling exotherms.

polymer, whose structure is mainly composed of phenyl propane units and benzene rings $[4,9,71]$. Hemicellulose has a random amorphous structure, is easily hydrolysed in strong acids, and has a shorter main molecular chain and therefore a lower degree of polymerization [9]. The presence of hemicellulose and lignin in the extracted wood flour filler and that of hemicellulose in the holocellulose filler, in the case of both wood species, implied the lack of significant $T_{\mathrm{m}}$ value changes (Table 4). Therefore, the small differences in $T_{\mathrm{m}}$ values between the examined two wood species are caused by the differences in their structures (i.e., crystallinity index, degree of polymerization, etc.).

The presence of fillers undoubtedly influenced the evolution of Gibbs energy $(\mathrm{G})$ and melting enthalpy $\left(\Delta \mathrm{H}_{\mathrm{m}}\right)$. For the biocomposites prepared from both wood species, $\Delta \mathrm{H}_{\mathrm{m}}$ values (Table 4) are influenced by filler degradation, caused by prolonged chemical treatments during their preparation. The nonlinear distribution of $\Delta \mathrm{H}_{\mathrm{m}}$ values in the case of white willow could be associated with the previously mentioned filler agglomeration and random selection of the samples for DSC analysis. Significant differences in terms of the degree of crystallinity $\left(X_{c}\right)$ can be also explained through Gibbs energy. The pronounced increase of $X_{c}$ values is most probably the direct consequence of adding extracted wood flour to the CA matrix, which acted as a surface nucleation reagent [72]. Crystallization is a three-stage process comprising super saturation of a solution, nucleation, and crystal growth. In the phase of super saturation, the chemical potential of solid matter must be lower than that of the same matter in melted form, which, in this case, is induced by rapid cooling of melted biocomposites. During cooling, due to the presence of the filler particles in the biocomposite structure, initial nucleation occurred directly on the surface of the filler particles. As nucleation was induced by the presence of foreign matters (i.e., fillers), it is a case of heterogeneous nucleation. In this type of nucleation, the presence of filler 
TABle 5: Density and mechanical properties of biocomposites prepared from white willow.

\begin{tabular}{lccccc}
\hline Type of filler & $N$ & Mean \pm STD & Median & Min & Max \\
\hline Density $\left(\mathrm{g} / \mathrm{cm}^{3}\right)$ & & & & & \\
$\quad$ Neat CA & 10 & $1.22 \pm 0.04$ & 1.23 & 1.10 & 1.27 \\
Extracted wood & 10 & $0.84 \pm 0.83^{\mathrm{a}}$ & 0.83 & 0.78 & 0.93 \\
Holocellulose & 10 & $0.86 \pm 0.04^{\mathrm{a}}$ & 0.86 & 0.81 & 0.95 \\
$\quad$ Alpha cellulose & 10 & $0.85 \pm 0.02^{\mathrm{a}}$ & 0.85 & 0.82 & 0.91 \\
Tensile strength (MPa) & & & & & \\
Neat CA & 10 & $64.14 \pm 8.88$ & 66.67 & 49.02 & 75.50 \\
Extracted wood & 10 & $28.10 \pm 3.10^{\mathrm{a}}$ & 27.30 & 24.00 & 31.14 \\
Holocellulose & 10 & $31.59 \pm 2.71^{\mathrm{a}}$ & 31.55 & 27.72 & 35.90 \\
Alpha cellulose & 10 & $29.71 \pm 2.95^{\mathrm{a}}$ & 29.88 & 25.29 & 34.52 \\
Tensile modulus (GPa) & & & & & \\
Neat CA & 10 & $2.29 \pm 0.12$ & 2.23 & 2.19 & 2.51 \\
Extracted wood & 10 & $1.22 \pm 0.06^{\mathrm{a}}$ & 1.21 & 1.15 & 1.36 \\
Holocellulose & 10 & $1.36 \pm 0.11^{\mathrm{b}}$ & 1.37 & 1.22 & 1.60 \\
$\quad$ Alpha cellulose & 10 & $1.30 \pm 0.55^{\mathrm{ab}}$ & 1.29 & 1.24 & 1.39 \\
Elongation at break (\%) & & & & & \\
Neat CA & 10 & $6.71 \pm 1.68$ & 7.04 & 4.37 & 9.83 \\
Extracted wood & 10 & $5.44 \pm 0.56^{\mathrm{a}}$ & 5.25 & 4.35 & 7.23 \\
Holocellulose & 10 & $5.26 \pm 0.51^{\mathrm{a}}$ & 5.20 & 4.31 & 6.01 \\
Alpha cellulose & 10 & $5.12 \pm 0.64^{\mathrm{a}}$ & 5.11 & 4.18 & 6.07 \\
\hline
\end{tabular}

Note: means sharing the same superscript are not significantly different from each other (Tukey's HSD, $p<0.05$ ).

contributes to lowering the value of the required nucleation energy and nuclei dissolution takes place as long as $\Delta \mathrm{G}$ value is positive. Gibbs energy changes in the negative direction as a consequence of heat release $(\Delta \mathrm{G}<0)$, and in the most thermodynamically favourable case, nucleation and spontaneous crystal growth occur. Based on that, it can be concluded that the filler that is the least chemically altered and degraded (i.e., extracted wood flour) has the most favourable surface nucleation properties. Since for the biocomposites prepared using holocellulose and alpha cellulose fillers the $X_{c}$ values are lower than those obtained for the composites prepared with extracted wood filler (Table 4), it can be additionally concluded that lignin is probably the initiator of nucleation. However, various authors report on the inhibitory effect of lignin on nucleation and crystallization, especially if lignin in the filler is present in larger quantities [33, 34, 36, 73]. Literature also suggests that the cellulose in the filler is responsible for the increase in nucleation abilities and that lignin is not capable of inducing epitaxy phenomena occurring on the matrix/filler interface [36]. Therefore, further consideration of this problem is necessary, especially in a system with a CA matrix, and that is something that we intend to work on in our further study. Low $X_{c}$ values of biocomposites prepared using alpha cellulose as fillers are most probably due to concentration of sodium hydroxide solution used for alpha cellulose preparation and formation of cellulose II polymorph which has lower nucleation ability as reported by Borysiak [34].
TABLE 6: Density and mechanical properties of biocomposites prepared from black alder.

\begin{tabular}{lccccc}
\hline Type of filler & $N$ & Mean \pm STD & Median & Min & Max \\
\hline Density $\left(\mathrm{g} / \mathrm{cm}^{3}\right)$ & & & & & \\
Neat CA & 10 & $1.27 \pm 0.03$ & 1.22 & 1.32 & 1.27 \\
Extracted wood & 10 & $0.86 \pm 0.05^{\mathrm{a}}$ & 0.86 & 0.79 & 0.94 \\
Holocellulose & 10 & $0.90 \pm 0.05^{\mathrm{a}}$ & 0.87 & 0.83 & 0.99 \\
Alpha cellulose & 10 & $0.89 \pm 0.06^{\mathrm{a}}$ & 0.91 & 0.77 & 0.97 \\
Tensile strength (MPa) & & & & & \\
Neat CA & 10 & $58.70 \pm 10.72$ & 58.71 & 40.77 & 74.05 \\
Extracted wood & 10 & $30.14 \pm 1.90^{\mathrm{a}}$ & 29.65 & 27.66 & 33.11 \\
Holocellulose & 10 & $30.43 \pm 4.39^{\mathrm{a}}$ & 30.33 & 23.49 & 38.98 \\
Alpha cellulose & 10 & $25.42 \pm 3.17^{\mathrm{a}}$ & 26.35 & 18.78 & 30.04 \\
Tensile modulus (GPa) & & & & & \\
Neat CA & 10 & $2.18 \pm 0.51$ & 2.07 & 1.60 & 3.27 \\
Extracted wood & 10 & $1.24 \pm 0.10^{\mathrm{a}}$ & 1.27 & 1.06 & 1.41 \\
Holocellulose & 10 & $1.35 \pm 0.06^{\mathrm{a}}$ & 1.33 & 1.29 & 1.45 \\
Alpha cellulose & 10 & $1.24 \pm 0.17^{\mathrm{a}}$ & 1.27 & 0.82 & 1.47 \\
Elongation at break (\%) & & & & & \\
Neat CA & 10 & $5.79 \pm 1.59^{\mathrm{a}}$ & 5.87 & 3.82 & 8.52 \\
Extracted wood & 10 & $5.17 \pm 0.56^{\mathrm{ab}}$ & 5.13 & 4.40 & 6.50 \\
Holocellulose & 10 & $4.67 \pm 0.72^{\mathrm{ab}}$ & 4.61 & 3.67 & 6.33 \\
Alpha cellulose & 10 & $4.61 \pm 0.38^{\mathrm{b}}$ & 4.53 & 4.03 & 5.34 \\
\hline
\end{tabular}

Note: means sharing the same superscript are not significantly different from each other (Tukey's HSD, $p<0.05$ ).

\subsection{Analysis of Mechanical Properties and Surface Morphology of Biocomposite Materials}

3.2.1. Mechanical Properties. The mechanical properties of the biocomposite materials prepared from white willow and black alder are presented in Tables 5 and 6 , respectively. The addition of fillers to the CA matrix resulted in a decrease of density in the case of both wood species. However, statistical analysis showed that there are no significant differences in the density of the composites as a function of the type of filler used. Therefore, the density decrease could be related to the presence of highly porous (hollow) fillers, which are not completely filled with polymer matrix.

The tensile strength and tensile modulus values of neat $\mathrm{CA}$, regardless of the examined wood species, are in the range of values of generic commercial CA (41 to $87 \mathrm{MPa}$ and 1.9 to 3.8 GPa, respectively), as stated by Paunonen [74]. However, there is a difference between the tensile strength values as a function of the wood species from which the CA was prepared (Tables 5 and 6). Those differences could be assigned to the bound acetyl group (\% acetyl) values that are different for the examined CA [75]. More precisely, the tensile strength value is lower in the case of the CA prepared from black alder, which had a lower \% acetyl value. Although it is common for the tensile modulus to increase with the addition of filler, data in Tables 5 and 6 show significant declines in both the tensile strength and modulus, regardless of the wood species. This can be explained with the low L/D ratio of filler particles (Table 1) and their agglomeration due to 


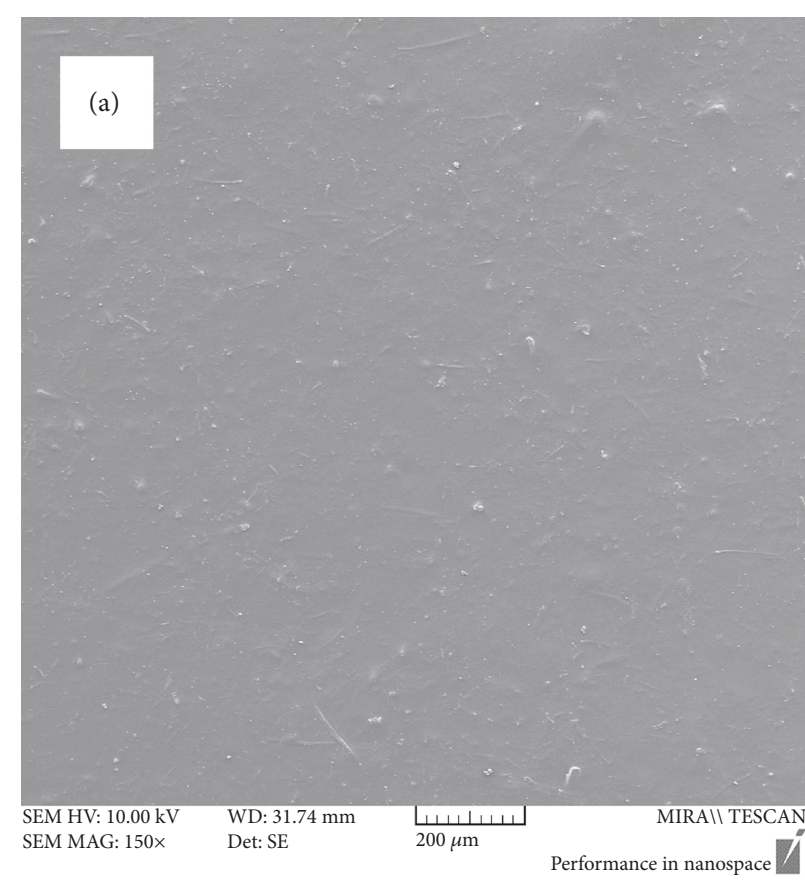

(a)

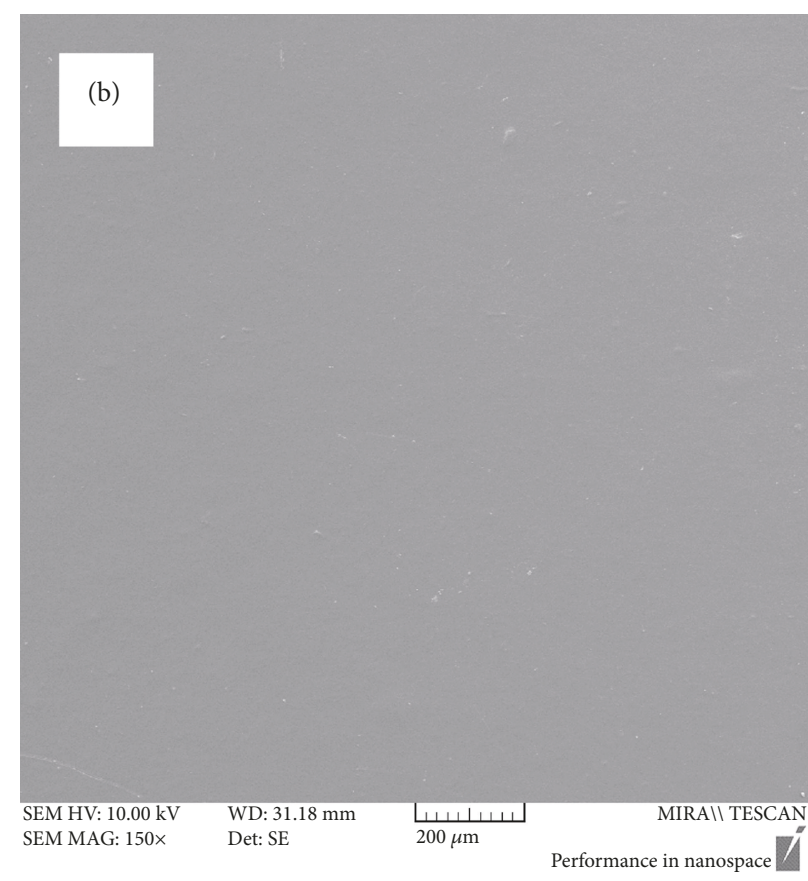

(b)

Figure 7: Surface morphology of neat CA films.

high van der Waals attraction forces [76] resulting with insufficient particle wetting. Additionally, it can be related with the polarity differences between the polymer matrix and the fillers $[33,77]$. The presence of agglomerated particles limit the load transfer from the matrix (additionally emphasized with the low $\mathrm{L} / \mathrm{D}$ ratio) to filler particles, and as a consequence, cracks in the structure of biocomposites form at much lower loads and propagate easily. $\mathrm{L} / \mathrm{D}$ ratios given in Table 1 and the results of mechanical testing (Tables 5 and 6) reveal that the slight rise in tensile strength and modulus in the case of holocellulose-filled composites is most probably due to a slightly higher L/D ratio of such fillers.

The influence of filler rigidity on the values of elongation at break can also be observed in Tables 4 and 5. The decline in the composites' elongation upon filler addition is caused by the low elongation of the fillers, which restricts the polymer molecules from flowing past one another [74].

If the results obtained in the present study are compared to the findings reported by other authors, it can be noted that the neat CA mechanical properties are somewhat similar. The small differences between our data and those provided in the literature can be attributed to the CA degree of substitution $[78,79]$, film thickness $[80,81]$, and plasticizer addition [81]. As for the biocomposites, it is rather difficult to compare the obtained results with the ones from the available literature. This is because the results obtained in different laboratories on natural filler-reinforced composites are often contradictory, as their properties depend on many factors, such as filler size and content, interface adhesion, fibre aspect ratio and orientation, fibre dispersion in the matrix, and stress transfer efficiency through the interface [82]. However, it is obvious that the addition of natural fillers affected the stiffness and decreased the elongation of the matrix. In order to improve the wetting and fibre-matrix adhesion, a compatibilizer should be added [83]. Still, the addition of the plasticizer would probably only partially solve the severe decline of mechanical properties, as the filler size should also be taken into consideration. This is because, in thin composites, nanoscaled fillers can act as reinforcement, while microscaled ones (as those used in this experiment) can decrease the mechanical properties of biocomposite materials [84]. Therefore, future experimental work should be done in order to investigate the effect of the addition of a compatibilizer and filler size reduction on the mechanical (thermal/morphological) properties of CA-based biocomposites.

3.2.2. Surface Morphology. The SEM micrographs in Figures 7(a) and 7(b) show the surfaces of neat CA films prepared from white willow and black alder. It can be seen that the CA film prepared from black alder (Figure 7(b)) has a smooth and even surface, while the one prepared from white willow (Figure 7(a)) exhibits a slightly rougher surface structure. As the unevenness on the surface of the white willowbased CA film resembles a fibre-like structure, its appearance could be associated with the presence of foreign matter and/or cellulose fibres, which have not been successfully acetylated. However, the transparency of the CA film prepared from white willow (transmittance $=29.5 \%$ ) is significantly lower than that of the film prepared from black alder (transmittance $=80.4 \%$; as measured at $550 \mathrm{~nm}$ ). Such high difference suggests that the water present in CA prior to dissolution and film casting [41] could have acted as a nonsolvent, thus initiating phase separation and leading to formation of the uneven and porous surface structure. As no pores have been noticed on the surfaces of the neat CA 


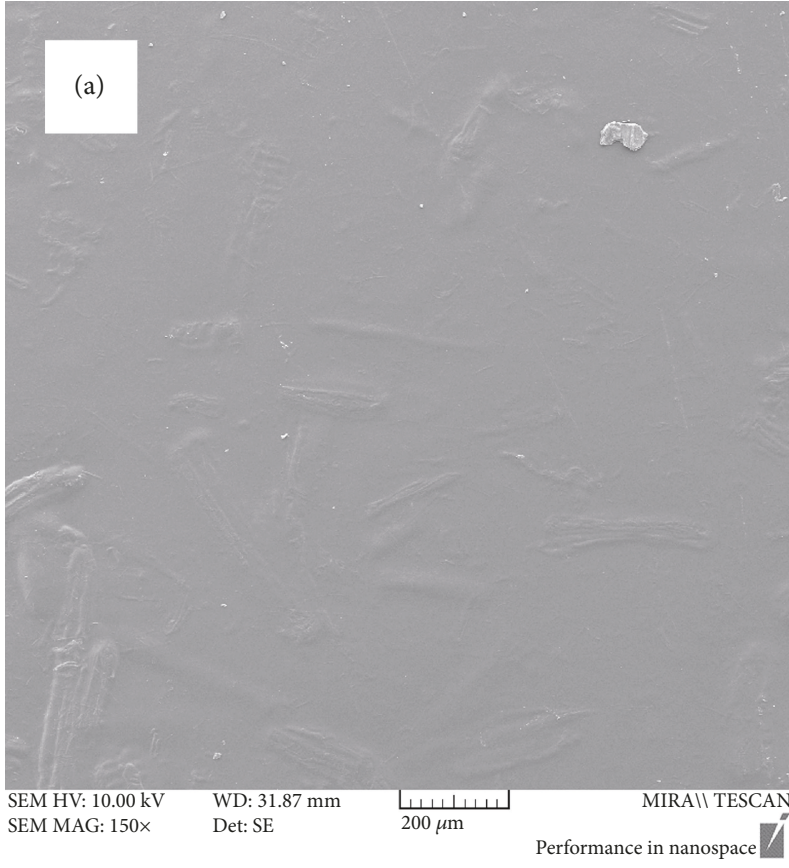

(a)

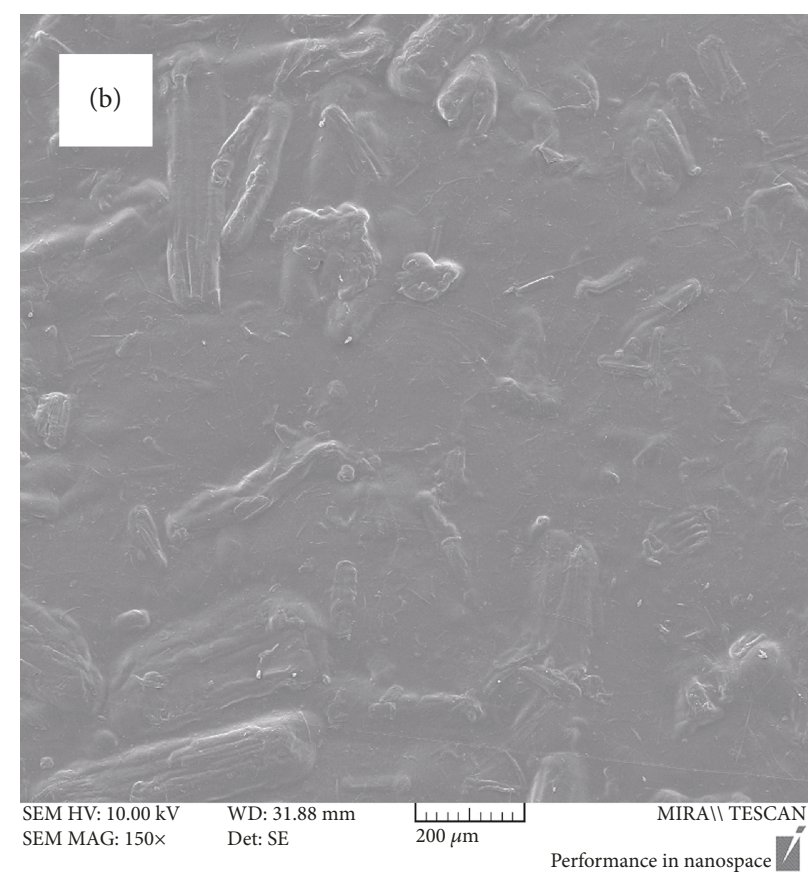

(b)

FIGURE 8: Surface morphology of biocomposites prepared using extracted wood as filler.

films (examined up to $10.000 \mathrm{x}$ magnification) and in order to verify whether the potential phase separation influenced the formation of the inner structure of the neat CA films, the porosity test was performed. It revealed that the structure of CA films was not porous (the porosity of the white willow-based CA film was $0.077 \%$ and that of the black alder-based CA was $0.062 \%$ ) but that there were some cracks in the film structure, which were most probably due to uneven shrinkage of the biopolymer during the process of solvent evaporation [85]. The low values of CA film transparency, in the case of white willow, can be associated with the presence of hemicelluloses (glucuronoxylane) in the isolated cellulose used for CA preparation [41]. The presence of hemicelluloses influenced the acetylation process and led to nonhomogeneous substitution [86], and the use of dichloromethane as solvent induced structural changes in the solution, which are governed by the amount of acetyl and hydroxyl groups on the partially substituted CA chains. Therefore, in the case of white willow, a nonhomogeneous polymer was synthesized, in which the loss of light transmission occurred.

Neat CA films exhibit almost identical morphological structures on both sides (i.e., the one facing the Petri dish bottom and the opposite one facing the Petri dish cover), while the surface morphologies on the two sides of the biocomposites are different for both wood species and all the types of fillers used. In Figure 8, the surface morphology of the white willow-based biocomposite prepared using extracted wood filler is shown. Figure 8(a) exhibits the side facing the Petri dish bottom and Figure 8(b) the upper side of the composite material.

The morphological difference between the two sides can be associated with the evaporation behaviour of the solvent and the fact that prolonged solvent evaporation caused the formation of thin (on average $240 \mu \mathrm{m}$ thick) films filled with partially overlapping filler particles. Quite slow evaporation of the solvent probably resulted in higher solvent pressure, thus forming smooth surfaces affected only by substrate roughness on the side facing the Petri dish bottom. As mentioned above, insufficient wetting caused the agglomeration of filler particles, thus leading to the formation of a rougher surface on the side facing the Petri dish cover. In Figure 9, the surface morphologies of the biocomposites prepared from white willow using holocellulose (Figure 9(a)) and alpha cellulose (Figure 9(b)) fillers are shown. Figures $9(\mathrm{c})$ and $9(\mathrm{~d})$ represent the morphologies of the biocomposites prepared from black alder filled with the same types of fillers. In all 4 cases, only the upper sides facing the Petri dish cover are shown, as the bottomside morphologies are almost identical to the ones showed in Figure 8(a).

As can be remarked from Figure 9(a)-9(d), filler particle agglomeration and overlaying occurred. Also, it is noticeable that some areas of the prepared biocomposites present lack filler, indicating that neat mechanical stirring resulted in the preparation of nonhomogeneous polymer/filler mixtures. In the case of the black alder-based biocomposite filled with alpha cellulose (Figure 9(d)), microcracks surrounding the filler particles are noticeable. The microcracks, particle agglomeration and particle-free spots in the thin films also had a significant influence on the mechanical properties of the biocomposites. Therefore, in further studies, alternative methods (e.g., using a high-speed homogenizer) of homogenization should be examined, alongside the previously mentioned considerations regarding the influence of filler size and plasticizer addition. 


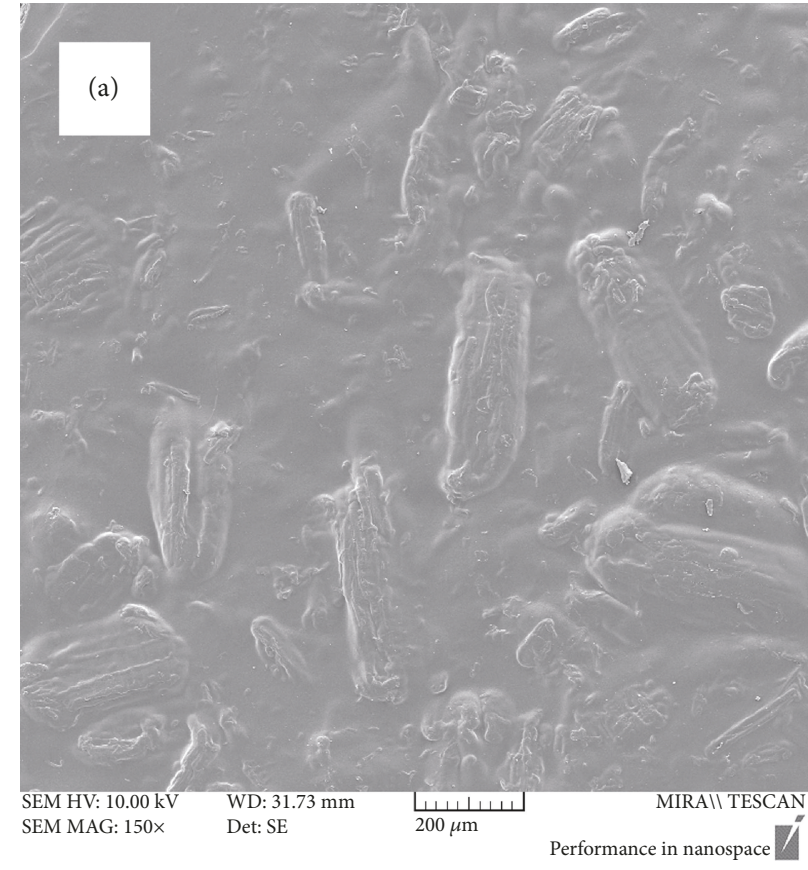

(a)

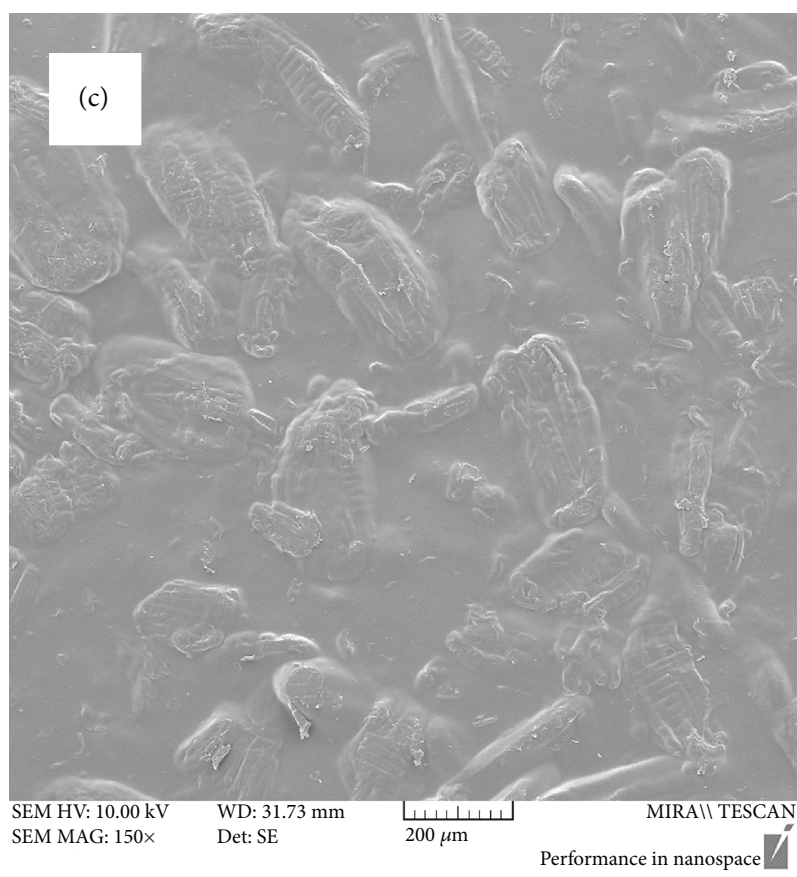

(c)

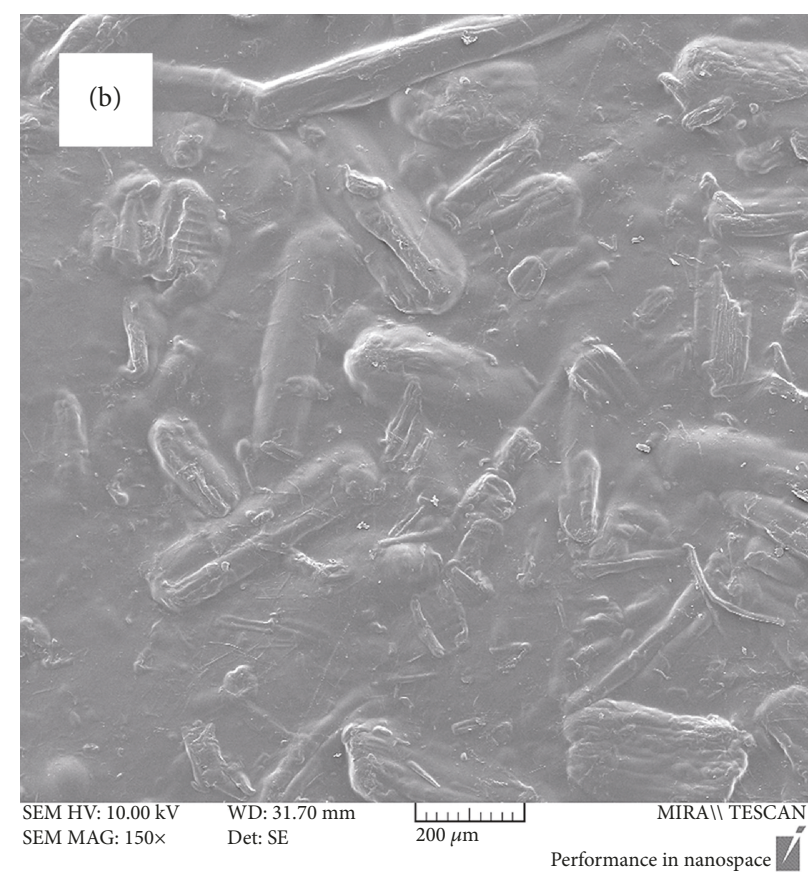

(b)

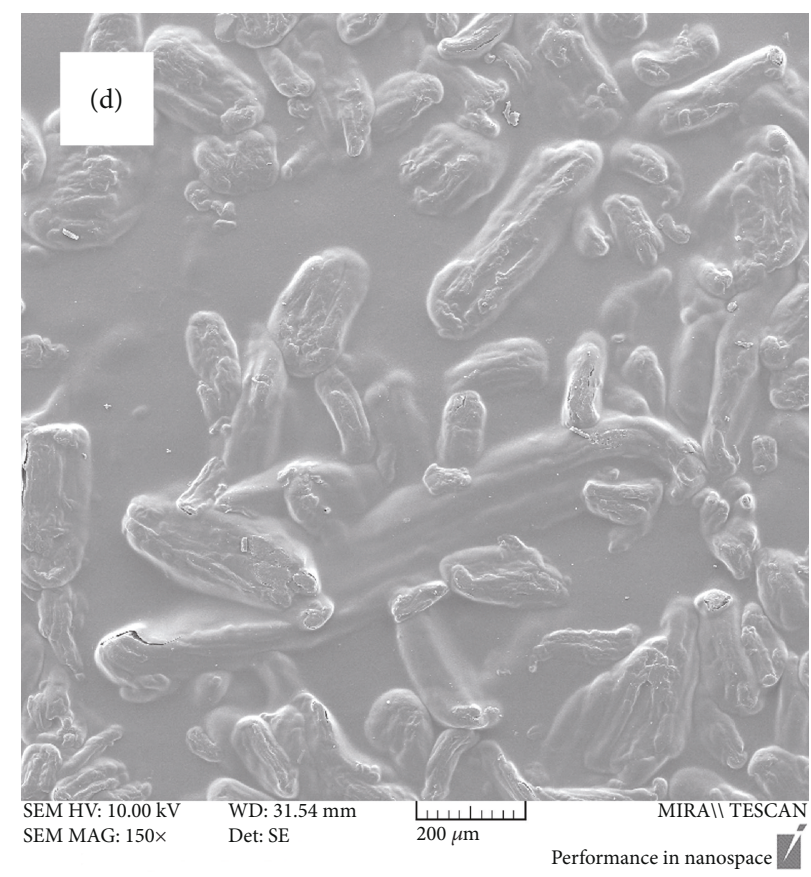

(d)

FIGURE 9: Surface morphologies of biocomposites prepared using holocellulose and alpha cellulose as fillers.

\section{Conclusions}

Biocomposites were prepared, using wood as the starting material for both the matrix and the filler preparation. Such composites were produced based on principles of welldefined (semi-) industrial processes (i.e., acetylation; solvent casting). Therefore, they represent an alternative rational use of somewhat industrially underutilized wood species, with the aim of producing high end-value products. How- ever, the obtained results emphasize the importance of properly selecting the raw material synthesis processes, as well as those for the production of biocomposites. The results also suggest the importance of filler particle chemical composition, size, L/D ratio, and their dispersion in a CA matrix on the properties of the achieved biocomposites. The seclusion of lignin due to prolonged chemical treatments, the formation of cellulose II polymorphic variety, and the more or less pronounced presence of certain crystalline allomorph (i.e., 
celluloses $\mathrm{I}_{\alpha}$ and $\mathrm{I}_{\beta}$ ) caused changes in thermal properties of fillers and composites, respectively. As the filler particle size was larger than the polymer matrix radius of gyration, the particle-rich phase segregated and fillers agglomerated during solvent casting of composites, thus causing changes in their thermal properties, surface morphology, and mechanical properties. Additionally, problems associated with the matrix-filler relationship, caused by polarity differences and insufficient wetting due to the filler's low L/D ratio, have been pointed out, leading to the conclusion that carbohydratebased fillers used in CA-based matrices acted as nonfunctional fillers, impairing the overall properties of the developed biocomposites.

Although this work undoubtedly demonstrated the possibility to produce biocomposites based on a single wood species for both the matrix and the filler, the results pointed out the need for conducting further experiments in order to finetune the structure and properties of CA-based biocomposites. Using higher purity CA and nanosized carbohydratebased fillers can be one of the possible research directions.

\section{Data Availability}

The data used to support the findings of this study are available from the corresponding author upon request.

\section{Conflicts of Interest}

The authors declare that there is no conflict of interest regarding the publication of this paper.

\section{Acknowledgments}

The authors wish to acknowledge the financial support of the Ministry of Science, Education and Sports of the Republic of Croatia (Project No. 068-0680457-0562).

\section{Supplementary Materials}

The Supplementary material consists of a figure in which the deconvoluted diffraction peaks for the samples S5 (top; holocellulose prepared from black alder) and S3 (bottom; alpha cellulose prepared from white willow) are shown. Peak deconvolution was done in order to determine the crystallinity indices of fillers, values of which are given in Table 3 . From the deconvoluted diffraction peaks for sample S3 (bottom), the formation of the cellulose II polymorph is clearly visible, with sample S5 (top) having the typical diffraction pattern of cellulose I. (Supplementary Materials)

\section{References}

[1] A. K. Mohanty, M. Misra, and L. T. Drzal, "Sustainable biocomposites from renewable resources: opportunities and challenges in the green materials world," Journal of Polymers and the Environment, vol. 10, no. 1/2, pp. 19-26, 2002.

[2] R. M. Johnson, N. Tucker, and S. Barnes, "Impact performance of Miscanthus/Novamont Mater-Bi ${ }^{\circledR}$ biocomposites," Polymer Testing, vol. 22, no. 2, pp. 209-215, 2003.
[3] A. Bismarck, A. Baltazar-y-Jimenez, and K. Sarikakis, "Green composites as panacea? Socio-economic aspects of green materials," Environment, Development and Sustainability, vol. 8, no. 3, pp. 445-463, 2006.

[4] R. M. Rowell, R. Pettersen, J. S. Han, J. S. Rowell, and M. A. Tshabalala, "Cell wall chemistry," in Handbook of Wood Chemistry and Wood Composites, R. M. Rowell, Ed., pp. 3574, CRC Press, Boca Raton, FL, USA, 2005.

[5] K. Jayaraman, "Manufacturing sisal-polypropylene composites with minimum fibre degradation," Composites Science and Technology, vol. 63, no. 3-4, pp. 367-374, 2003.

[6] D. B. Easty and N. S. Thompson, "Wood analysis," in Wood Structure and Composition, M. Lewin and I. S. Goldstein, Eds., pp. 49-138, Marcel Dekker, New York, NY, USA, 1991.

[7] S. Saka, "Chemical composition and distribution," in Wood and Cellulosic Chemistry - Second Edition, Revised and Expanded, D. N.-S. Hon and N. Shiraishi, Eds., pp. 51-81, Marcel Dekker, New York, NY, USA, 2001.

[8] D. N.-S. Hon, "Functional natural polymers: a new dimensional creativity in lignocellulosic chemistry," in Chemical Modification of Lignocellulosic Materials, D. N.-S. Hon, Ed., pp. 1-10, Marcel Dekker, New York, NY, USA, 1996.

[9] D. Fengel and G. Wegener, Wood - Chemistry, Ultrastructure, Reactions, Verlag Kessel, Remagen, Germany, 2003.

[10] E. Samios, R. K. Dart, and J. V. Dawkins, "Preparation, characterization and biodegradation studies on cellulose acetates with varying degrees of substitution," Polymer, vol. 38, no. 12, pp. 3045-3054, 1997.

[11] J. Puls, S. A. Wilson, and D. Hölter, "Degradation of cellulose acetate-based materials: a review," Journal of Polymers and the Environment, vol. 19, no. 1, pp. 152-165, 2011.

[12] K. J. Edgar, C. M. Buchanan, J. S. Debenham et al., "Advances in cellulose ester performance and application," Progress in Polymer Science, vol. 26, no. 9, pp. 1605-1688, 2001.

[13] S. Fischer, K. Thümmler, B. Volkert, K. Hettrich, I. Schmidt, and K. Fischer, "Properties and applications of cellulose acetate," Macromolecular Symposia, vol. 262, no. 1, pp. 89-96, 2008.

[14] A. M. Farooque, A. Al-Amoudi, and K. Numata, "Degradation study of cellulose triacetate hollow fine-fiber SWRO membranes," Desalination, vol. 123, no. 2-3, pp. 165-171, 1999.

[15] Y. Wang, L. Yang, G. Luo, and Y. Dai, "Preparation of cellulose acetate membrane filled with metal oxide particles for the pervaporation separation of methanol/methyl tert-butyl ether mixtures," Chemical Engineering Journal, vol. 146, no. 1, pp. 6-10, 2009.

[16] W.-L. Chou, D.-G. Yu, and M.-C. Yang, "The preparation and characterization of silver-loading cellulose acetate hollow fiber membrane for water treatment," Polymers for Advanced Technologies, vol. 16, no. 8, pp. 600-607, 2005.

[17] A. Cano-Odena, M. Spilliers, T. Dedroog, K. De Grave, J. Ramon, and I. F. J. Vankelecom, "Optimization of cellulose acetate nanofiltration membranes for micropollutant removal via genetic algorithms and high throughput experimentation," Journal of Membrane Science, vol. 366, no. 1-2, pp. 25-32, 2011.

[18] E. Saljoughi, M. Sadrzadeh, and T. Mohammadi, "Effect of preparation variables on morphology and pure water permeation flux through asymmetric cellulose acetate membranes," Journal of Membrane Science, vol. 326, no. 2, pp. 627-634, 2009. 
[19] R. Abedini, S. M. Mousavi, and R. Aminzadeh, "A novel cellulose acetate (CA) membrane using $\mathrm{TiO}_{2}$ nanoparticles: preparation, characterization and permeation study," Desalination, vol. 277, no. 1-3, pp. 40-45, 2011.

[20] P. Pandey and R. S. Chauhan, "Membranes for gas separation," Progress in Polymer Science, vol. 26, no. 6, pp. 853-893, 2001.

[21] P. Zadorecki and A. J. Michell, "Future prospects for wood cellulose as reinforcement in organic polymer composites," Polymer Composites, vol. 10, no. 2, pp. 69-77, 1989.

[22] S. Kamel, "Nanotechnology and its applications in lignocellulosic composites, a mini review," Express Polymer Letters, vol. 1, no. 9, pp. 546-575, 2007.

[23] A. Dufresne, "Processing of polymer nanocomposites reinforced with polysaccharide nanocrystals," Molecules, vol. 15, no. 6, pp. 4111-4128, 2010.

[24] G. Siqueira, J. Bras, and A. Dufresne, "Cellulosic bionanocomposites: a review of preparation, properties and applications," Polymers, vol. 2, no. 4, pp. 728-765, 2010.

[25] M. J. Zaini, M. Y. A. Fuad, Z. Ismail, M. S. Mansor, and J. Mustafah, "The effect of filler content and size on the mechanical properties of polypropylene/oil palm wood flour composites," Polymer International, vol. 40, no. 1, pp. 51-55, 1996.

[26] A. K. Rout and A. Satapathy, "Study on mechanical and tribo-performance of rice-husk filled glass-epoxy hybrid composites," Materials and Design, vol. 41, pp. 131-141, 2012 .

[27] M. A. AlMaadeed, Z. Nogellova, M. Micusik, I. Novak, and I. Krupa, "Mechanical, sorption and adhesive properties of composites based on low density polyethylene filled with date palm wood powder," Materials and Design, vol. 53, pp. 29-37, 2014.

[28] F. Le Digabel and L. Avérous, "Effects of lignin content on the properties of lignocellulose-based biocomposites," Carbohydrate Polymers, vol. 66, no. 4, pp. 537-545, 2006.

[29] G. David, N. Gontard, and H. Angellier-Coussy, "Mitigating the impact of cellulose particles on the performance of biopolyester-based composites by gas-phase esterification," Polymers, vol. 11, no. 2, pp. 200-218, 2019.

[30] H. Ni'mah, E. O. Ningrum, D. Nur Rizkiyah, I. G. A. Gede Chandra Divita, and M. A. Subaghio, "Effect of particle size and crystallinity of cellulose filler on the properties og poly(L-lactic acid): mechanical property and thermal stability," AIP Conference Proceedings, vol. 1840, article 090009, 2017.

[31] A. Treimanis, M. Laka, S. Chernyavskaya et al., "Microcrystalline cellulose fillers for use in hybrid composites with polyethylene and lignin," Cellulose Chemistry and Technology, vol. 50, pp. 117-125, 2016.

[32] M. Lenes and $\varnothing$. W. Gregersen, "Effect of surface chemistry and topography of sulphite fibres on the transcrystallinity of polypropylene," Cellulose, vol. 13, no. 4, pp. 345-355, 2006.

[33] D. Paukszta and S. Borysiak, "The influence of processing and the polymorphism of lignocellulosic fillers on the structure and properties of composite materials-a review," Materials, vol. 6, no. 7, pp. 2747-2767, 2013.

[34] S. Borysiak, "Influence of wood mercerization on the crystallization of polypropylene in wood/PP composites," Journal of Thermal Analysis and Calorimetry, vol. 109, no. 2, pp. 595603, 2012.
[35] S. Borysiak, "Influence of cellulose polymorphs on the polypropylene crystallization," Journal of Thermal Analysis and Calorimetry, vol. 113, no. 1, pp. 281-289, 2013.

[36] A. Grząbka-Zasadzińska, Ł. Klapiszewski, K. Bula, T. Jesinowski, and S. Borysiak, "Supermolecular structure and nucleation ability of polylactide-based composites with silica/lignin hybrid fillers," Journal of Thermal Analysis and Calorimetry, vol. 126, no. 1, pp. 263-275, 2016.

[37] TAPPI, T $257 \mathrm{~cm}$-12 Sampling and preparing wood for analysis, TAPPI Press, Atlanta, GA, USA, 2012.

[38] TAPPI, T $204 \mathrm{~cm}-97$ Solvent extractives of wood and pulp, TAPPI Press, Atlanta, GA, USA, 1997.

[39] B. L. Browning, Methods of Wood Chemistry - Volume II, John Wiley\&Sons - Interscience Publishers, New York, NY, USA, 1967.

[40] TAPPI, T $203 \mathrm{~cm}$-99 Alpha-, beta- and gamma-cellulose in pulp, TAPPI Press, Atlanta, GA, USA, 2009.

[41] N. Španić, V. Jambreković, S. Medved, and A. Antonović, "Chemical and thermal properties of cellulose acetate prepared from white willow (Salix alba) and black alder (Alnus glutinosa) as a potential polymeric base of biocomposite materials," Chemical and Biochemical Engineering Quarterly, vol. 29, no. 3, pp. 357-365, 2015.

[42] ASTM D817-96, Standard test methods of testing cellulose acetate propionate and cellulose acetate butyrate, ASTM International, West Conshohocken, PA, USA, 1996.

[43] D. A. Cerqueira, G. R. Filho, and R. M. N. Assunção, "A new value for the heat of fusion of a perfect crystal of cellulose acetate," Polymer Bulletin, vol. 56, no. 4-5, pp. 475-484, 2006.

[44] E. Jin, J. Guo, F. Yang et al., "On the polymorphic and morphological changes of cellulose nanocrystals (CNC-I) upon mercerization and conversion to CNC-II," Carbohydrate Polymers, vol. 143, pp. 327-335, 2016.

[45] ASTM D882-02, Standard test method for tensile properties of thin plastic sheeting, ASTM International, West Conshohocken, PA, USA, 2002.

[46] ASTM D1003-07, Standard test method for haze and luminous transmittance of transparent plastics, ASTM International, West Conshohocken, PA, USA, 2007.

[47] C. F. Wang, Y. An, Q. H. Li, S. J. Wan, W. X. Chen, and X. D. Liu, "Nonsolvent effects on morphology of cellulose acetate films prepared by dry-cast process," Journal of Macromolecular Science, Part B, vol. 51, no. 11, pp. 2266-2275, 2012.

[48] H. Yang, R. Yan, H. Chen, C. Zheng, D. H. Lee, and D. T. Liang, "In-depth investigation of biomass pyrolysis based on three major components: hemicellulose, cellulose and lignin," Energy Fuels, vol. 20, no. 1, pp. 388-393, 2006.

[49] H.-S. Kim, S. Kim, H.-J. Kim, and H.-S. Yang, "Thermal properties of bio-flour filled polyolefin composites with different compatibilizing agent type and content," Thermochimica Acta, vol. 451, no. 1-2, pp. 181-188, 2006.

[50] T. Sebio-Puñal, S. Naya, J. López-Beceiro, J. Tarrío-Saavedra, and R. Artiaga, "Thermogravimetric analysis of wood, holocellulose, and lignin from five wood species," Journal of Thermal Analysis and Calorimetry, vol. 109, no. 3, pp. 1163-1167, 2012.

[51] A. N. Shebani, A. J. van Reenen, and M. Meincken, "The effect of wood extractives on the thermal stability of different wood species," Thermochimica Acta, vol. 471, no. 1-2, pp. 43-50, 2008. 
[52] Y. Chen, M. A. Tshabalala, J. Gao, N. M. Stark, Y. Fan, and R. E. Ibach, "Thermal behavior of extracted and delignified pine wood flour," Thermochimica Acta, vol. 591, pp. 40-44, 2014.

[53] P. Jandura, B. Riedl, and B. V. Kokta, "Thermal degradation behavior of cellulose fibers partially esterified with some long chain organic acids," Polymer Degradation and Stability, vol. 70, no. 3, pp. 387-394, 2000.

[54] A. R. Martin, M. A. Martins, O. R. R. F. da Silva, and L. H. C. Mattoso, "Studies on the thermal properties of sisal fiber and its constituents," Thermochimica Acta, vol. 506, no. 1-2, pp. 14-19, 2010.

[55] L. Gašparovič, J. Labovský, J. Markoš, and L.'. Jelemenský, "Calculation of kinetic parameters of the thermal decomposition of wood by distributed activation energy model (DAEM)," Chemical and Biochemical Engineering Quarterly, vol. 26, pp. 45-53, 2012.

[56] M. G. Grønli, G. Várhegyi, and C. Di Blasi, “Thermogravimetric analysis and devolatilization kinetics of wood," Industrial and Engineering Chemistry Research, vol. 41, no. 17, pp. 4201-4208, 2002.

[57] M. Brebu and C. Vasile, "Thermal degradation of lignin - a review," Cellulose Chemistry and Technology, vol. 44, pp. 353-363, 2010.

[58] M. Poletto, A. J. Zattera, M. M. C. Forte, and R. M. C. Santana, "Thermal decomposition of wood: influence of wood components and cellulose crystallite size," Bioresource Technology, vol. 109, pp. 148-153, 2012.

[59] K. K. Pandey, "A study of chemical structure of soft and hardwood and wood polymers by FTIR spectroscopy," Journal of Applied Polymer Science, vol. 71, no. 12, pp. 1969-1975, 1999.

[60] J. Baeza and J. Freer, "Chemical characterization of wood and its components," in Wood and Cellulosic Chemistry - Second Edition, Revised and Expanded, D. N.-S. Hon and N. Shiraishi, Eds., pp. 275-384, Marcel Dekker, New York, NY, USA, 2001.

[61] K. K. Pandey and A. J. Pitman, "FTIR studies of the changes in wood chemistry following decay by brown-rot and white-rot fungi," International Biodeterioration \& Biodegradation, vol. 52, no. 3, pp. 151-160, 2003.

[62] X. Colom, F. Carillo, F. Nogués, and P. Garriga, "Structural analysis of photodegraded wood by means of FTIR spectroscopy," Polymer Degradation and Stability, vol. 80, no. 3, pp. 543-549, 2003.

[63] A. D. French, "Idealized powder diffraction patterns for cellulose polymorphs," Cellulose, vol. 21, no. 2, pp. 885-896, 2014.

[64] R. Boy, G. Narayanan, and R. Kotek, "Formation of cellulose and protein blend biofibers," in Polysaccaride-Based Fibers and Composites: Chemical and Engineering Fundamentals and Industrial Applications, L. Lucia and A. Ayoub, Eds., pp. 77-117, Springer, Cham, Switzerland, 2018.

[65] J.-F. Sassi, P. Tekely, and H. Chanzy, "Relative susceptibility of the I $\alpha$ and I $\beta$ phases of cellulose towards acetylation," Cellulose, vol. 7, no. 2, pp. 119-132, 2000.

[66] F. Danusso, M. Levi, G. Gianotti, and S. Turri, "End unit effect on the glass transition temperature of low-molecular-weight polymers and copolymers," Polymer, vol. 34, no. 17, pp. 3687-3693, 1993.

[67] E. H. Immergut and H. F. Mark, "Principles of plasticization," in Plasticization and Plasticizer Processes, N. A. J. Platzer, Ed., pp. 1-26, American Chemical Society, Washington, DC, USA, 1965.

[68] G. Wypych, "Effect of plasticizers on properties of plasticized materials," in Handbook of Plasticizers, G. Wypych, Ed., pp. 193-272, ChemTec Publishing, Toronto, Canada, 2nd edition, 2012.

[69] B. Mohebby, "Application of ATR infrared spectroscopy in wood acetylation," Journal of agricultural Science and Technology, vol. 10, pp. 253-259, 2008.

[70] H. M. Shaikh, K. V. Pandare, G. Nair, and A. J. Varma, "Utilization of sugarcane bagasse cellulose for producing cellulose acetates: novel use of residual hemicellulose as plasticizer," Carbohydrate Polymers, vol. 76, no. 1, pp. 23-29, 2009.

[71] E. Adler, "Lignin chemistry - past, present and future," Wood Science and Technology, vol. 11, no. 3, pp. 169-218, 1977.

[72] H. Bouafif, A. Koubaa, P. Perre, A. Cloutier, and B. Riedl, "Wood particle/high-density polyethylene composites: thermal sensitivity and nucleating ability of wood particles," Journal of Applied Polymer Science, vol. 113, no. 1, pp. 593-600, 2009.

[73] R. A. Pérez-Camargo, G. Saenz, S. Laurichesse et al., "Nucleation, crystallization, and thermal fractionation of poly( $\varepsilon$-caprolactone)-grafted-lignin: effects of grafted chains length and lignin content," Journal of Polymer Science. Part $B$, vol. 53, no. 24, pp. 1736-1750, 2015.

[74] S. Paunonen, "Strength and barrier enhancements of cellophane and cellulose derivative films: a review," BioResources, vol. 8, pp. 3098-3121, 2013.

[75] R. J. Newton Jr, D. Dunn, J. Yuan, and N. M. Clipse, "Formulation effects on the thermomechanical properties and permeability of free films and coating films: characterization of cellulose acetate films," Pharmaceutical Technology, vol. 33, pp. 88-100, 2009.

[76] J. Ervina, M. Mariatti, and S. Hamdan, "Effect of filler loading on the tensile properties of multi-walled carbon nanotube and graphene nanopowder filled epoxy composites," Procedia Chemistry, vol. 19, pp. 897-905, 2016.

[77] A. K. Bledzki and J. Gassan, "Composites reinforced with cellulose based fibres," Progress in Polymer Science, vol. 24, no. 2, pp. 221-274, 1999.

[78] J. Gutierrez, S. Carrasco-Hernandez, H. S. Barud et al., "Transparent nanostructured cellulose acetate films based on the self assembly of PEO-b-PPO-b-PEO block copolymer," Carbohydrate Polymers, vol. 165, pp. 437-443, 2017.

[79] D. L. Morgado, B. V. M. Rodrigues, E. V. R. Almeida, O. A. El Seoud, and E. Frollini, "Bio-based films from linter cellulose and its acetates: formation and properties," Materials, vol. 6, no. 6, pp. 2410-2435, 2013.

[80] J. Lu and L. T. Drzal, "Microfibrillated cellulose/cellulose acetate composites: effect of surface treatment," Journal of Polymer Science Part B: Polymer Physics, vol. 48, no. 2, pp. 153$161,2010$.

[81] Z.-Y. Yang, W.-J. Wang, Z.-Q. Shao, H.-D. Zhu, Y.-H. Li, and F.-J. Wang, "The transparency and mechanical properties of cellulose acetate nanocomposites using cellulose nanowhiskers as fillers," Cellulose, vol. 20, no. 1, pp. 159-168, 2013.

[82] A. Dufresne, D. Dupeyre, and M. Paillet, "Lignocellulosic flour-reinforced poly(hydroxybutyrate-co-valerate) composites," Journal of Applied Polymer Science, vol. 87, no. 8, pp. 1302-1315, 2003. 
[83] A. K. Mohanty, A. Wibowo, M. Misra, and L. T. Drzal, "Effect of process engineering on the performance of natural fiber reinforced cellulose acetate biocomposites," Composites Part A: Applied Science and Manufacturing, vol. 35, no. 3, pp. 363-370, 2004.

[84] D. M. Panaitescu, A. N. Frone, M. Ghiurea, C. I. Spataru, C. Radovici, and M. D. Iorga, "Properties of polymer composites with cellulose microfibrils," in Advances in Composite Materials - Ecodesign and Analysis, B. Attaf, Ed., pp. 103122, InTech, Rijeka, Croatia, 2001.

[85] Y. Zhou, X. Luo, L. Huang, S. Lin, and L. Chen, "Development of ionic liquid-mediated antibacterial cellulose-chitosan films," Journal of Biobased Materials and Bioenergy, vol. 9, no. 4, pp. 389-395, 2015.

[86] R. H. F. Beck, M. Fitton, and H. R. Kricheldorf, "Chemical modification of polysaccharides," in Handbook of Polymer Synthesis Part B, H. R. Kricheldorf, Ed., pp. 1517-1578, Marcel Dekker, New York, NY, USA, 1992. 


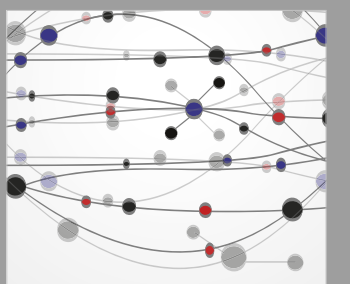

The Scientific World Journal
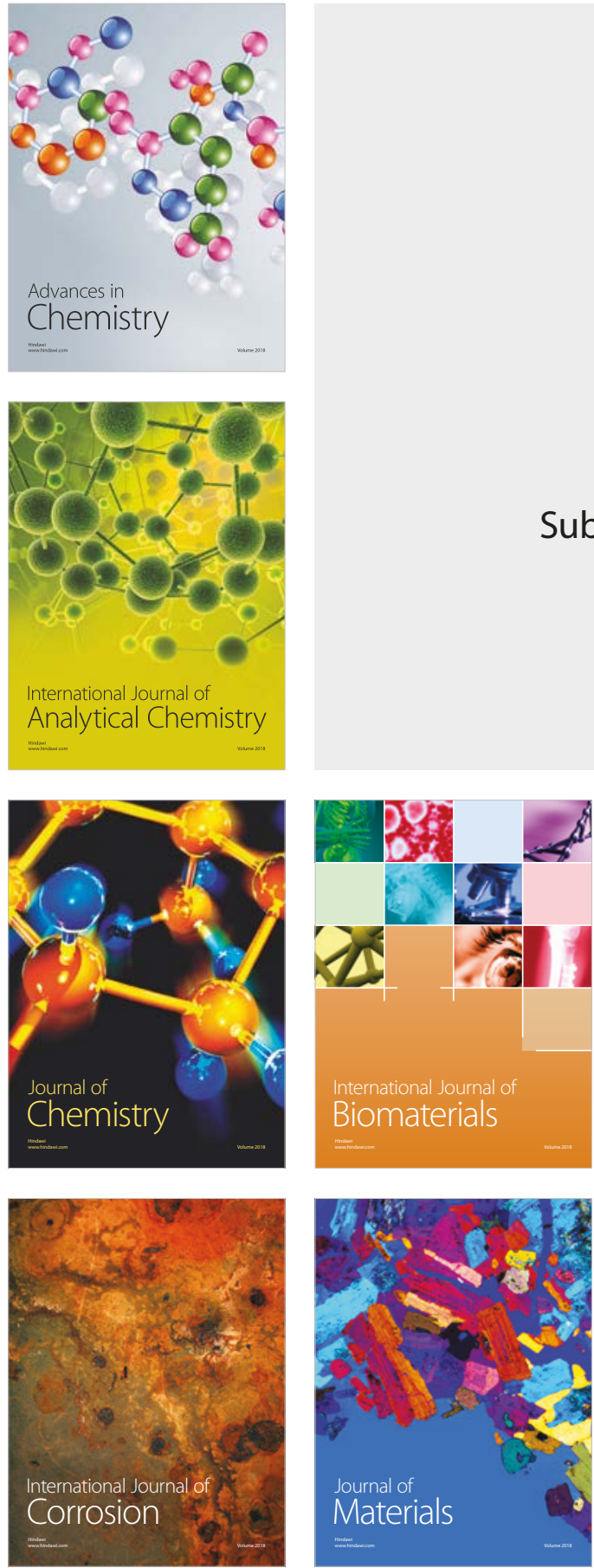

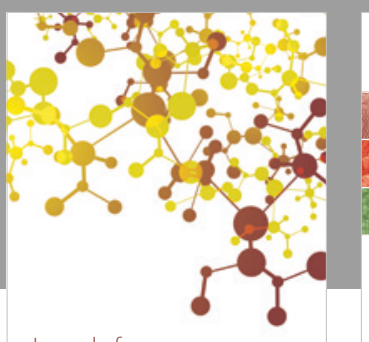

Journal of

Applied Chemistry
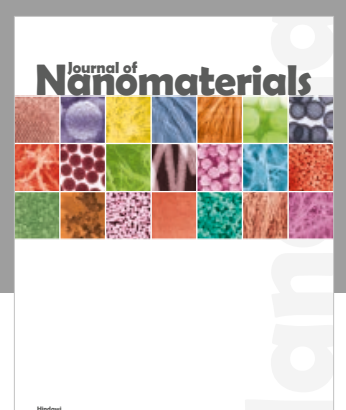

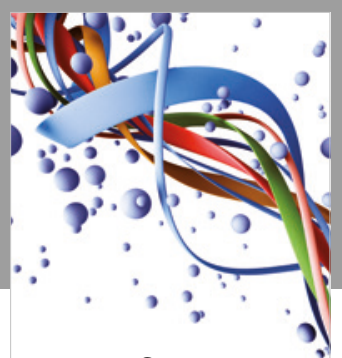

Scientifica

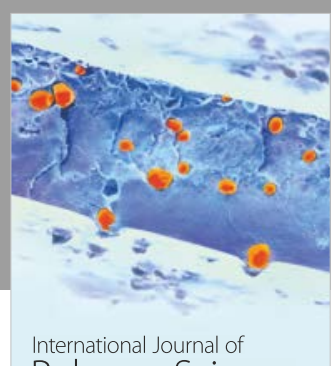

Polymer Science

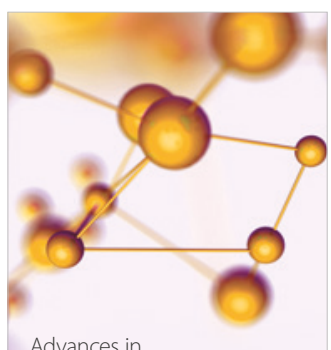

Physical Chemistry
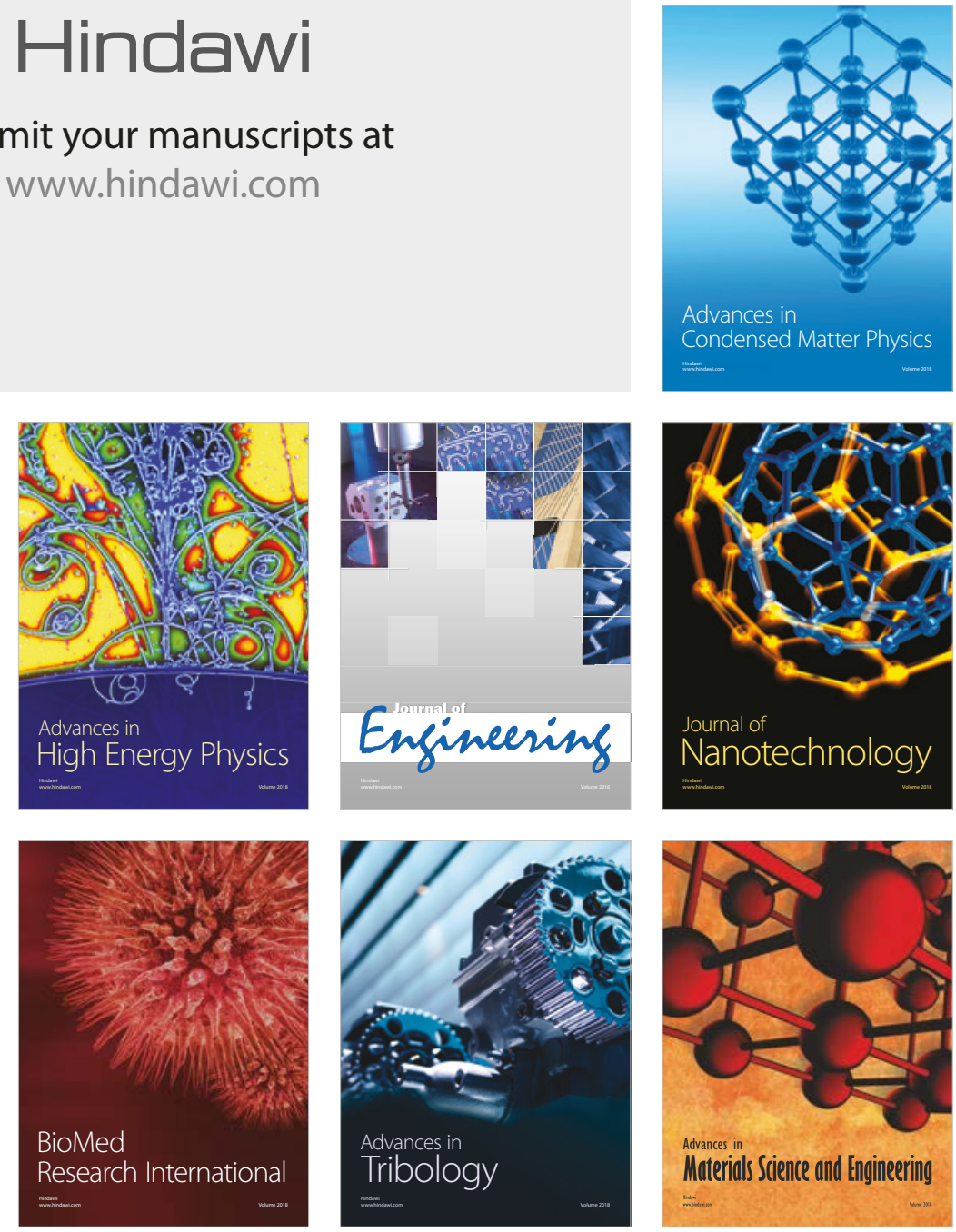